\title{
14 „Kinder bringen Glück“: Lebens- und Paarberatung in NS-Deutschland und in der Schweiz
}

„Kinder bringen Glück“1 lautet ein zentraler Lehrsatz im Eheratgeber „Ein Leben zu Zweien“ des Autors Walther von Hollander von $1940 .^{2}$ Doch das „Glück, Kinder zu haben“3, sei nicht selbstverständlich:

„Wer sich einbildet, man könne in der Lotterie mit geringem Einsatz das ganz große Glück gewinnen, der kann auch glauben, daß man ohne Einsatz hübsche, gesunde, prächtig gedeihende Kinder bekommen kann, an deren mühelosem Aufwachsen und herrlichem Gedeihen man Tag für Tag seine Freude hat.“4

Wie begründet Hollander sein Ratgeberwissen? Kinder zu bekommen, komme der „Schönheit der kinderreichen Frau“ in vielerlei Hinsicht zugute:

„Eine Frau, die ein Kind verantwortlich empfängt, trägt, gebiert und nährt [...], wird abgesehen von allen seelischen Bereicherungen, rein körperlich schöner, gesunder und leistungsfähiger. [...] Fast alle Drüsen haben sich gekräftigt, sind infolge der Anstrengungen auf das Höchstmaß ihrer Leistungsfähigkeit gekommen, wenn die Frau die neun Monate bis zur Geburt und die - mindestens - neun Monate des Stillens hinter sich gebracht hat. Da sie außerdem durch das Kind aus dem sonstigen Leben ferngehalten wird, in ein Leben besonderer natürlicher Rhythmen hineingeführt, findet gleichzeitig eine seelische und geistige Kräftigung und Verselbständigung statt, so daß sie schließlich frischer, jünger, schöner und leistungsfähiger aus der Kampfzone zurückkehrt. Dieser Prozess erweitert sich [...], daß viele Frauen beim zweiten, dritten oder vierten Kind erst ihre wahre Schönheit entfalten. “5

Hollander entwirft in seinem Ratgeber eine weibliche Körperpolitik als eine leistungsorientierte Körperpraktik, der eine affirmative Gefühlspolitik zugrunde liegt. In wissenshistorischer Analogie zum arbeitspsychologischen „Mensch-Maschine"6-Modell sieht Hollander den Frauenkörper pervertiert als rationalisierbare Maschine, welche durch das Gebären von Kindern das „Höchstmaß ihrer Leis-

\footnotetext{
1 Hollander 1940a.

2 Vgl. ebd.

3 Ebd.

4 Ebd, 226.

5 Hollander 1940b, 232f.

6 Vgl. From Mimetic Machines to Digital Organisms. The Transformation of the Human Motor. In: Rabinbach 2018, 1-27, 18.
}

Ә OpenAccess. (c) 2021 Isabelle Haffter, publiziert von De Gruyter. (cc) BY-NC-ND Dieses Werk ist lizenziert unter einer Creative Commons Namensnennung - Nicht kommerziell - Keine Bearbeitung 4.0 International Lizenz. https://doi.org/10.1515/9783110661439-014 
tungsfähigkeit“ erreiche. „Das Glück, Kinder zu haben“"7 steht bei Hollander zudem in einer militärstrategischen Analogie zur „Kampfzone“, aus welcher die stereotypisierte „Frau als Gebärerin“8 nach Ablauf der Schwangerschafts-, Geburts- und Stillzeit als „Führerin“9 „frischer, jünger, schöner und leistungsfähiger"10 hervortrete.

Hollanders biologistisches, metaphysisches und zugleich psychotechnisches Ratgeberwissen über eine leistungsorientierte Körperpolitik eines kinderreichen „Mutterglücks“11 sowie sein körperpolitischer Rat an seine Leserinnen, „hübsche, gesunde, prächtig gedeihende Kinder“ zu gebären, muss vor dem Hintergrund der „rassenhygienischen“ NS-Geburtenpolitik untersucht werden.

Ausgehend von Hollanders Ratschlägen an Ehepaare zum Erlangen eines „rassenhygienischen“ „Mutterglücks“ sollen in einem transnationalen Vergleich pädagogischer, psychologischer, medizinischer und „rassenhygienischer“ Lebens-, Frauen-, Paar-, Ehe-, Mutterschafts- und Elternratgeber folgende Forschungsfragen beantwortet werden: 1 . Welche gesellschaftliche Bedeutung wurde einem „Mutterglück“ nach 1933 im Vergleich zur Weimarer Republik ${ }^{12}$ und zur $\mathrm{BRD}^{13}$ zugeschrieben ${ }^{14}$ 2. Welche stereotypisierten Vor- und Gegenbilder eines Frauenideals wurden im Wissenskontext eines „Mutterglücks“ entworfen? 3. Welche Bedeutung besaß ein individuelles „Glück“ einer Frau als „Mutter“15 im

7 Hollander 1940b, 230.

8 Ebd., 233.

9 Ebd.

10 Ebd., 232.

11 Groß 1942, 62, 64.

12 Als exemplarische Auswahl für die vergleichende Analyse dienen folgende Ratgeber aus der Weimarer Zeit: Peters 1920a, Peters 1920b, Keyserling 1925, Kaupe und Küster 1928, Ankenbrand 1932. Aus Platzgründen kann nicht auf jede Ausgabe einzeln eingegangen werden. Zur Forschung über die Ratgeberliteratur der Weimarer Republik vgl. u.a. Kleiner und Suter 2015, Senne und Hesse 2019.

13 Als exemplarische Auswahl für die vergleichende Analyse dienen folgende Ratgeber aus der BRD: Günther 1951, Hollander 1955, Hollander 1961.

14 Zur Geschichte der Erziehungs- und Elternratgeber in der Weimarer Republik vgl. Brunner 2008, Volk 2017. Zu Elternratgebern und den darin entworfenen Mutterbildern in der NS-Zeit vgl. Zur Ratgeberliteratur in der NS-Zeit. In: Höffer-Mehlmer 2003, 182-210, Schmid 2008.

15 Ein Beispiel für einen nationalsozialistischen Ratgeber für Väter ist der streckenweise durchaus ironisch verfasste Ratgeber „Der Vater und sein erstes Kind“ von Ernst Heimeran aus dem Jahr 1938, der 1941 in 45.000 Exemplaren erschien und noch 1956 in 21. Auflage veröffentlicht wurde. Vgl. Heimeran, Ernst. 1942. Der Vater und sein erstes Kind, 7. Aufl., 36.-45. Tsd., München: Heimeran. Eine weiterführende Untersuchung zum „deutschen Vater“ mit Blick auf die geschlechtergeschichtliche Konstruktion eines ,Männlichkeitsdiskurses‘ in der NS-Ratgeberliteratur wäre sicher aufschlussreich. Es hätte den Rahmen dieser Untersuchung jedoch gesprengt. 
NS-Regime? Und 4. welche biografischen Lebensgeschichten, Semantiken, Metaphern, Lebensräume, Geschlechterstereotypen, Objekte und Handlungspraktiken wurden in den Ratgeberanleitungen zum Erlangen eines „Mutterglücks“ genannt?

Zur geschlechterspezifischen Analyse des Glückswissens in den Diskursen über weibliche Sexualität ${ }^{16}$, Partnerwahl, Berufstätigkeit und Mutterschaft soll in einem transnationalen Vergleich mit der Schweiz ${ }^{17}$ erforscht werden, inwiefern sich Wandel, Ambivalenzen und Kontinuitäten über ein „Mutterglück“ zwischen 1933 und 1945 nachweisen lassen. ${ }^{18}$

Das Ziel der Analyse ist es, den Wandel vom leistungsorientierten Erfolgstypus der Selbstrationalisierungsdiskurse zum „rassenhygienischen“ Führungstypus am Beispiel der Ratgeberliteratur für die „deutsche Frau“19 aus einer geschlechterspezifischen Perspektive zu untersuchen. Ein „Mutterglück“ in Form eines „rassenhygienischen“ Kinderreichtums wurde für die „deutsche Frau“ in den Lebens-, Beziehungs-, Ehe- und Mutterschaftsratgebern als eine selbstdisziplinarische und autosuggestive Leistungskultur und zugleich auf der Grundlage einer nationalsozialistischen „Rassenmoral“ als „Glück“ verheißende Lebensführung propagiert. Die Untersuchung will aufzeigen, dass das von der NSErziehungspolitik geforderte „Mutterglück“ in einem engen Zusammenhang mit den „rassenhygienischen Moralvorstellungen der leistungsorientierten NS-Arbeitspolitik „Kraft durch Freude“ stand. Am Beispiel der massenmedialen Ratgeberliteratur in NS-Deutschland ${ }^{20}$ kann veranschaulicht werden, wie emotionspolitische Wissenskonzepte von „Liebe“, „Ehe“, „Glück“ „Treue“, „Pflichten“, „Opferbereitschaft“, „arischer“ Lebensführung und „völkischer“ „Verantwortung“ als „rassenhygienische“ Körperpraktiken einer „arischen“ Lebensführung der „deutschen“ Frau, Mutter und Erzieherin zentral verhandelt wurden.

16 Zur Geschichte des Sexualitätsdiskurses in der Ratgeberliteratur vgl. Bänziger u. a. 2010.

17 Als exemplarische Auswahl für die vergleichende Analyse dienen folgende Ratgeber aus der Schweiz: Pautsch 1925, Arbeitsgemeinschaft der Neutralen Auskunfts- und Beratungsstelle für Frauen 1934, Wyler 1935, Guggenbühl 1936, Känel 1936, Baumgarten 1943, Haenni-Wyss 1945. Aus Platzgründen kann nicht auf jede Ausgabe einzeln eingegangen werden.

18 Zur Ratgeberliteratur in der Schweiz, 1945-1970, vgl. Mühlestein 2009.

19 Zum Begriff vgl. u.a. Diehl 1933. Zur „Verpflichtung und Aufgabe der Frau im nationalsozialistischen Staat“ vgl. u.a. Scholtz-Klink 1936.

20 Als exemplarische Auswahl für die vergleichende Analyse dienten folgende Ratgeber aus NSDeutschland: Schilfarth 1934, Graaz 1935, Hollander 1938, Haarer 1939, Elster 1939a, Elster 1939b, Rott 1939, Hollander 1940b, Hollander 1945. Aus Platzgründen kann nicht auf jede Ausgabe einzeln eingegangen werden. 


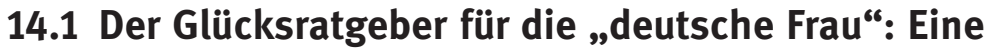 „rassenhygienische“ NS-Geburtenpolitik}

Was verstand die Ratgeberliteratur unter dem wissenshistorischen Begriff der „deutschen Frau“ und welche Bedeutung und Aufgabe hatte diese in der „Volksgemeinschaft“ zu übernehmen? Guida Diehl (1868-1961) ${ }^{21}$ beschreibt die „deutsche Frau“ in ihrem Ratgeber „Die deutsche Frau und der Nationalsozialismus“ (1933) als neuen Menschentypus, jedoch im hegemonialen Abgleich zum Vorbildcharakter des „deutsche[n] Mann[es]“:

„Genau so wie wir Frauen ein heldisches, charaktervolles Mannestum in unserem Volke forderten, wie es uns beschämte und niederdrückte, als dasselbe schwand und das öffentliche Leben von ganz anderen Männern gestaltet wurde, wie es uns beglückt, wenn heldisches Sein wieder durchbricht, - genau so will der deutsche Mann an dem Frauentum seiner Nation einen Durchbruch zu seinem wahren Wesen erleben. Er will es verehren können in seiner Herzenskraft, seiner Reinheit und seiner Mutterwürde. Die deutsche Seele ersehnt ein Frauentum, das wirklich ,zu edler Tat begeistert', für das es sich lohnt, zu kämpfen und zu sterben.“22

Vom Standpunkt des männlichen „Volksgenossen“ zeichne sich die „deutsche Frau“ durch „Herzenskraft“, „Reinheit“ und „Mutterwürde“ aus. Diese Eigenschaft würden den Mann wiederum emotionspolitisch „zu edler Tat begeistern“, wie es auch in der NS-Nationalhymne, dem „Lied der Deutschen“, als kollektivistische Gefühlspolitik besungen wurde. ${ }^{23}$

21 Zur Biografie vgl. Lange 1998.

22 Diel 1933, 5.

23 Diese Zeile ist eine Referenz an die erste Strophe des „Deutschlandliedes“ oder auch „Das Lied der Deutschen“ genannt, welche während des Nationalsozialismus vor dem „Horst-WesselLied“ gesungen wurde. 1841 wurde der Liedtext von August Heinrich Hoffmann von Fallersleben (1798-1874) verfasst. Die Musik stammt von Franz Josef Haydn (1732-1809). 1949 verzichtete das deutsche Grundgesetz auf die Festschreibung einer Nationalhymne, zumal Zeilen wie „Deutschland, Deutschland über alles“ nach dem Zweiten Weltkrieg unaufführbar waren. (Vgl. u.a. Escher 2017, 11) Seit 1991 gilt die dritte Strophe des „Deutschlandliedes“ als deutsche Nationalhymne. Für eine Wissensgeschichte über „Glück“ ist die aktuelle Fassung besonders aufschlussreich, da sie die Politik einer deutschen ,Glückskultur als explizite Gefühlspolitik eines nationalen, prosperierenden „Glücks“ besingt und die wissenshistorische Kontinuität dieser Wissenspraktik bis in die Gegenwart der demokratischen Bundesrepublik Deutschland einmal mehr unter Beweis stellt: „Einigkeit und Recht und Freiheit für das deutsche Vaterland! Danach lasst uns alle streben, brüderlich mit Herz und Hand! Einigkeit und Recht und Freiheit sind des Glückes Unterpfand: Blüh im Glanze dieses Glückes, blühe, deutsches Vaterland!“ Vgl. Die Nationalhymne der Bundesrepublik Deutschland, https://www.bundesregierung.de/breg-de/suche/ die-nationalhymne-der-bundesrepublik-deutschland-461412, 12.09.2020. 
Was war ein zentrales Merkmal des sozialen Wandels der „deutschen Frau“ im Nationalsozialismus? Laut Diehl zeichne sich das „Hinaustreten der Frau in die Mitarbeit an den öffentlichen Aufgaben und am gesamten Volksleben“ aus. ${ }^{24}$ Der „Kampf um die Frauenseele“ sei als „Frauenfrage für den Nationalsozialismus von größter Bedeutung“, so Diehl. ${ }^{25}$ Die Gründung des „Kampfbund[s] für deutsche Frauenkultur“ sollte 1933 auf die Reformierung der inneren Lebensführung abzielen. Im ambivalent metaphysischen und neonietzscheanischen Kontext einer Willenskraftlehre entwirft Diehl das Konzept einer energetischen „Kraft“ des „neue[n] deutsche[n] Frauenwille[ns]“ in Analogie zum „kämpfenden Manneswillen“, der alle Frauen als „Volksgenossinnen“ vereine und gesellschaftsübergreifend in eine „gesunde[...], kraftvolle[...] deutsche[...] Zukunft“ führen solle. ${ }^{26}$ Die „deutsche Frau“ hatte jedoch im Selbstverständnis der NS-Geburtenpolitik einen zentralen, „rassenhygienischen“ Auftrag zu erfüllen, der mit der vordergründig propagierten Gleichstellung der Geschlechter in der „Volksgemeinschaft“ nicht vereinbar war: „Der Familie, dem Volk, der Rasse Kinder zu schenken.“27

Mit pathetischen Worten betont auch die Ärztin und Ratgeberautorin Johanna Haarer (1900 - 1988) in ihrem Frauenratgeber „Die deutsche Mutter und ihr erstes Kind“ den Entindividualisierungsprozess der „werdenden Mutter“ im „,völkergeschichtlich“ überhöhten Kontext des staatlich verordneten Auftrags einer „rassenhygienischen“ Geburtenpolitik:

„Kein Ereignis im Leben der Frau entreißt sie aber auch so sehr ihrem Einzelschicksal und ordnet sie ein in das große Geschehen des Völkerlebens wie dieser Gang an die Front der Mütter unseres Volkes, die den Strom des Lebens, Blut und Erde unzähliger Ahnen, die Güter des Volkstums und der Heimat, die Schätze der Sprache, Sitte und Kultur weitertragen und auferstehen lässt in einem neuen Geschlecht.“28

In wissenshistorischer Kontinuität wurde Haarers Ratgeber auch noch nach 1945, unter Bereinigung des nationalsozialistischen Vokabulars, mit dem Titel „Die Mutter und ihr erstes Kind“" aufgelegt. Allein dieser Ratgeber erreichte seit seiner Ersterscheinung im Jahr 1934 eine Gesamtauflage von 1.2 Millionen Exemplaren. ${ }^{29}$

Die Leser*innen sollten Haarers Vorstellung von einer „rassenhygienischen“ Gefühlskultur mit Hilfe einer selbsterzieherischen Körperpraktik Folge leisten.

24 Vgl. Diel, 1933, 4.

25 Vgl. ebd., 6.

26 Vgl. ebd.

27 Ebd., 9.

28 Haarer 1939, 5.

$29 \mathrm{Zu}$ Haarers Ratgeber vgl. Chamberlain 2016. Zur Biografie, vgl. https://www.univie.ac.at/bio grafiA/daten/text/bio/haarer.htm, 19.09.2020. 
Diese selbsterzieherische Anweisung war kein Einzelfall, sondern wurde in der Ratgeberliteratur massenmedial verbreitet. Die folgenden Analysen sollen diese These weiterführend unter Beweis stellen.

\section{2 „Mutterglück“: Eine transnationale Ikone einer weiblichen Körperpolitik}

Bereits im März 1934 wurde den Besucher`innen der Ausstellung „Erbgesund Erbkrank“ an der Invalidenstraße 138 in Berlin die „rassenhygienische“ Geburtenpolitik und ein damit angeblich im Zusammenhang stehendes „Mutterglück“ vor Augen geführt. ${ }^{30}$ Die Ausstellung „Erbgesund - Erbkrank“ fand im Kontext des Gesetzerlasses „zur Verhütung erbkranken Nachwuchses“ statt, der rechtlich seit dem 1. Januar 1934 in Kraft getreten war. ${ }^{31}$

Der „Rassenhygieniker“ und NS-Ministerialbeamte Gottfried Frey (1871-1952) erläutert, ausgehend von der Ausstellung „Erbgesund - Erbkrank“, die propagandistische Bedeutung von großangelegten Ausstellungen als „Hilfsmittel zur Aufklärung“ der Bevölkerung in seiner Schrift „Hygienische Erziehung im Volksgesundheitsdienst“" von 1934:

„Seit der Machtübernahme legte die nationalsozialistische Regierung besonderen Wert auf Ausstellungen, die die Sonderart deutschen Wesens und deutsche volksgesundheitliche Forderungen betonen. So eröffnete im Jahre 1933 das Messeamt der Stadt Berlin mit dem Deutschen Hygienemuseum die Ausstellung ,Die Frau' mit der Einleitungsgruppe ,Volk ohne Jugend: Volk ohne Zukunft'. Die feierliche Ansprache des Ministers für Volksaufklärung und Propaganda kennzeichnete die außerordentliche Bedeutung, die die nationale Regierung dieser Frage beimißt.“32

Zur Illustration der menschenverachtenden NS-Gesellschaftsutopie, die auf der wissenshistorischen Kontinuität der „Internationalen Hygieneausstellung“ von 1930 und 1931 aufbaute, wurden den Besucher^innen der Ausstellung „Erbgesund - Erbkrank“ zahlreiche Propagandafotografien präsentiert.

Die nationalsozialistische Moralvorstellung eines kinderreichen „Mutterglücks“, wie dies die gleichnamige Fotografie im Zentrum der abgebildeten

30 Vgl. Frey 1934, 69.

31 „Gesetz zur Verhütung erbkranken Nachwuchses. Vom 14. Juli 1933. RGBl, Nr. 86, 25. Juli 1933, S. 529-351 (Inkraft: 1. Januar 1934), ALEX Historische Rechts- und Gesetzestexte Online, Österreichische Nationalbibliothek, http://alex.onb.ac.at/cgi-content/alex?apm=0\&aid=dra\&datum= $19330004 \&$ seite $=00000529 \& z 00 m=2,04.09 .2020$.

32 Frey 1934, $68 \mathrm{f}$. 
Ausstellungswand illustriert (Abb. 12), setzte die NS-Familienpolitik im Sinne der geschlechterstereotypisierten, „rassenmoralischen“ Lebensführung bedingungslos voraus. ${ }^{33}$ Ein „,rassenhygienisches“ „Mutterglück“ manifestiere sich in einem „erbgutgesunden“ Kindersegen, so lautete eine zentrale „volksaufklärerische“ Botschaft der Ausstellung. Dieses „rassenhygienische“ „Mutterglück“ wurde als Vorbildfunktion einer weiblich-stereotypisierten Körperpraktik propagiert und in den emotionspolitischen Kontext der Arbeitsmoral „Kraft durch Freude“ einer nationalsozialistischen Gefühlskultur gestellt. ${ }^{34}$

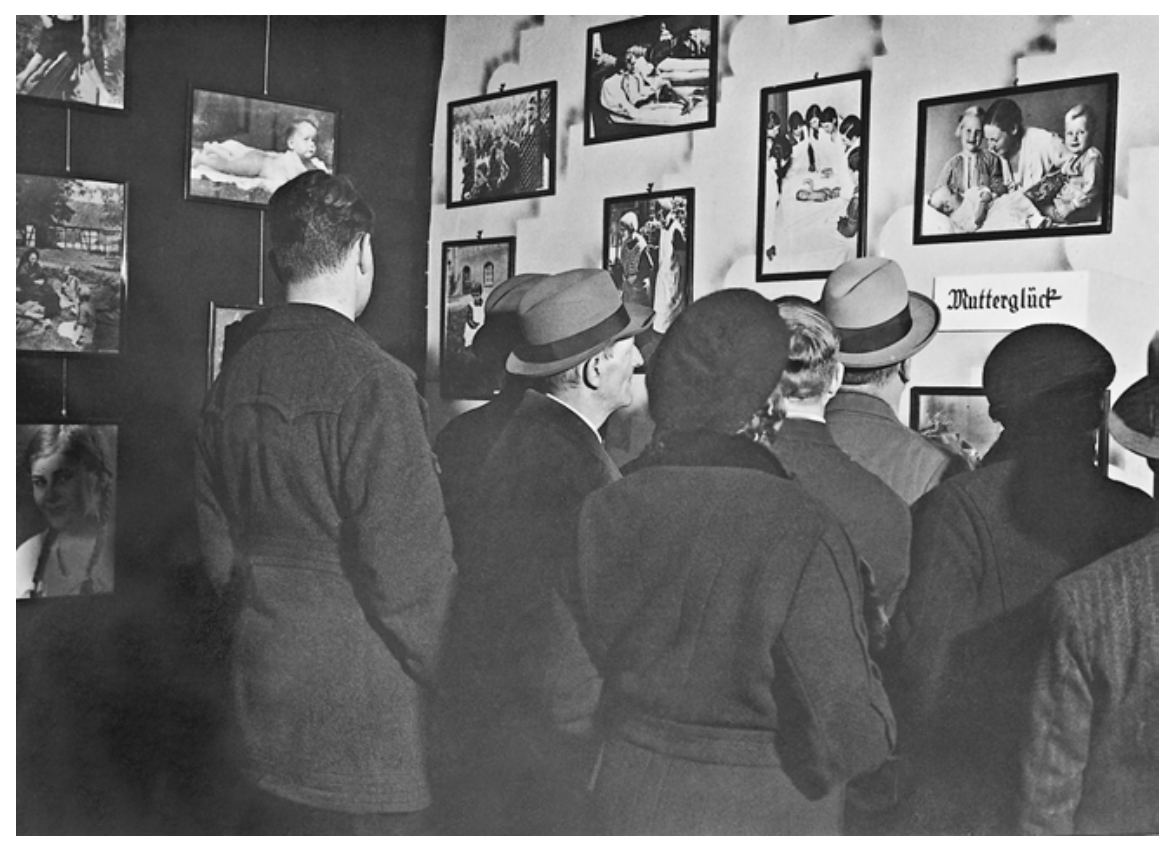

Abb. 12: [Besucher*innen betrachten fotografiertes „Mutterglück“], NS-Ausstellung „Erbgesund-Erbkrank“, Berlin, 1934

33 Vgl. Groß 1942, 62, 64.

34 Eine weitere Ausstellung zum Thema „,Deutsches Volk - Deutsche Arbeit““ wurde im April 1934, „[...] als Beispiel eines ungebrochenen Lebenswillens der Nation“ organisiert. Dort wurde den Besucher^innen die „Entstehung des deutschen Volkes, seine Rassenkunde und -Hygiene, das Reich der Deutschen (Römisches Reich deutscher Nation, Reich Bismarcks, das Dritte Reich), die Arbeitsbeschaffung für alle und die Leistung der deutschen Arbeit“ im Sinne der NS-Arbeitsideologie präsentiert. Vgl. Frey 1934, 69. 
Der Frage nach einer „rassenhygienischen“ NS-Geburtenpolitik wurde im NSRegime „größte Bedeutung“ zugemessen. ${ }^{35}$ Dabei unterschied die NS-Geburtenpolitik „rassenhygienisch“ zwischen einem „erbgesunden“ und einem „erbkranken“ Nachwuchs. Die gleichnamige Ausstellung sollte jedem „Volksgenossen vor Augen“ führen, „welche Gefahren die Erbkrankheiten für unser Volkstum bedeuten und welche Gründe zu dem ,Gesetz zur Verhütung erbkranken Nachwuchses“ Anlaß gaben.“36 Das „volksaufklärerische“ und leistungsorientierte Selbsterziehungskonzept „,Erbgesund - Erbkrank“ stand im Kontext einer Reihe weiterer Ausstellungen zur „NS-Rassenhygiene““.37

Um den Wirkungskreis der Propagandaausstellungen nicht nur auf das großstädtische Publikum zu beschränken, waren diese Veranstaltungen als „Wanderausstellungen“ konzipiert worden: „Da sie [die Wanderausstellungen] das Volk aufsuchen, wo es ansässig ist, besitzen sie unter Umständen einen noch umfassenderen Einfluß als die nur in den Großstädten ausführbaren Hygieneausstellungen der geschilderten Art“, lautete die propagandistische Begründung. ${ }^{38}$ Zudem wurden die Ausstellungsmaterialien an Schulen verteilt. Dabei griff das Propagandaministerium zwecks museumspädagogischer Wissensvermittlung auch auf Ausstellungsunterlagen aus der Zeit der Weimarer Republik zurück:

„So wurde aus der Sonderschau der Reichsregierung ,Die Entwicklung des deutschen Gesundheitswesens، auf der Dresdener Internationalen Hygieneausstellung 1930 und 1931 die Abteilungen: [...] Fürsorge für Mutter und Kind, Fürsorge für psychisch Abnorme [...] weiten Kreisen der Bevölkerung, insbesondere auch Lehrern und Schülern zugänglich gemacht.“"39

Zwei Jahre später, 1936, erfuhren die Besucher^innen der Ausstellung „Kommunismus ohne Maske“ von den katastrophalen Zuständen in der UdSSR, die angeblich in keinem Verhältnis zu den Errungenschaften der NS-Familien- und „Rassenpolitik“ stünden. ${ }^{40}$

Das Propagandaplakat „Mutterglück“ (Abb. 13) visualisierte auch in dieser Ausstellung die nationalsozialistische Politik einer affirmativen Gefühlskultur

35 Vgl. Frey 1934, 68 f.

36 Ebd., 69.

37 In Berlin wurde beispielsweise im Bezirksamt Tiergarten eine Ausstellung zur „Familienforschung, Vererbungslehre, Erbgesundheitslehre und Rassenfragen“ gezeigt. Vgl. Frey 1934.

38 Vgl. Frey 1934.

39 Ebd.

40 Die Ausstellung basierte auf der gleichnamigen Propagandaschrift, die Goebbels 1936 bereits in 11. Auflage publizierte und seine Rede auf dem „Reichsparteitag“ von 1935 beinhaltete. Vgl. Goebbels 1936. 


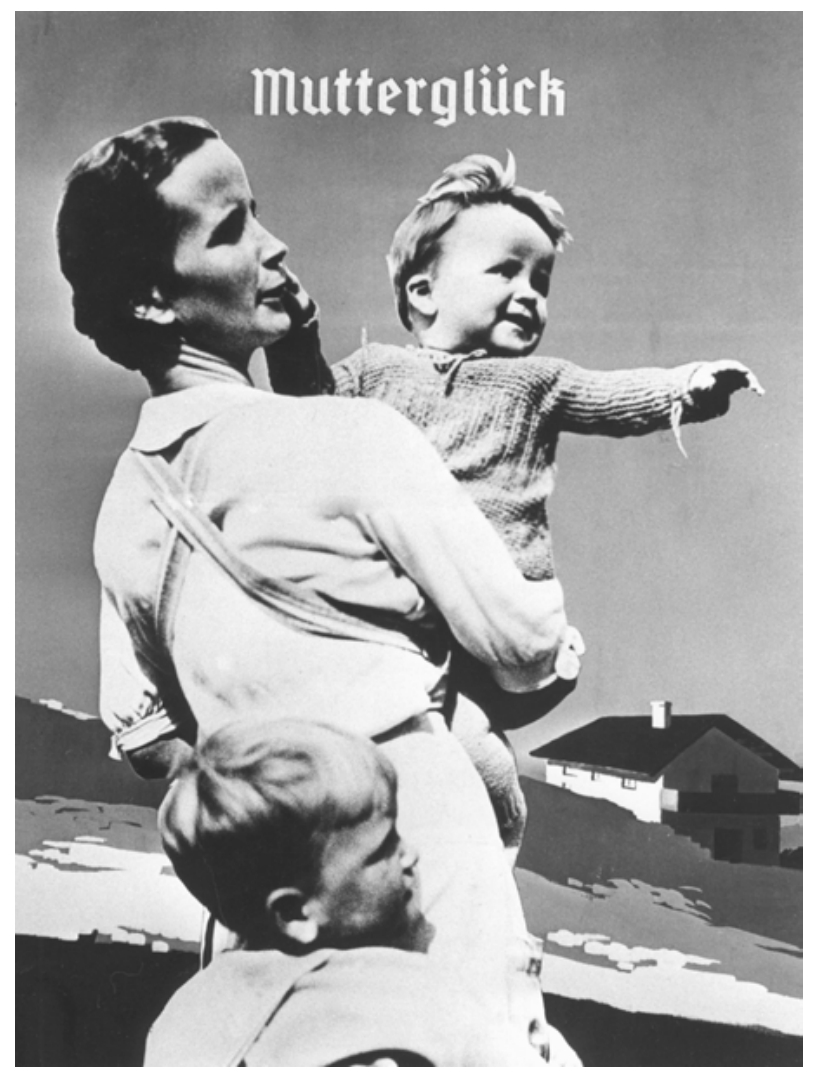

Abb. 13: „Mutterglück“: „Dieses Bild sagt alles, so geht es bei uns der deutschen Mutter. Dem Führer haben wir es zu danken, dass in Deutschland Glück und Zufriedenheit herrscht!“, [Originaler Fototext], NS-Propagandaausstellung „Kommunismus ohne Maske“, Berlin, 1936

„der deutschen Mutter“411. Dazu wurde die ikonologische Bildbotschaft der collagierten Fotografie mit einem entsprechend emotionspolitischen Propagandatext unterlegt:

„Dieses Bild sagt alles, so geht es bei uns der deutschen Mutter. Dem Führer haben wir es zu danken, dass in Deutschland Glück und Zufriedenheit herrscht!“42

Bezeichnend für die emotionspolitische Ikonografie eines „Mutterglücks“ dürfte die Darstellung der stereotypisierten „deutschen Mutter“ mit ihren zwei Söhnen

41 Originaler Fototextausschnitt von Abb. 13, vgl. Abbildungsverzeichnis.

42 Originaler Fototext von Abb. 13, vgl. Abbildungsverzeichnis. 
sein. Diese Darstellung entfaltete in der landesweiten Wanderausstellung eine fotoästhetisch konstruierte und geschlechterstereotypisierte Wirkungsmacht auf die rezeptive Wahrnehmung der Ausstellungsbesucher`innen, wie sie auch in ikonografischen Variationen in Zeitschiften, Ratgebern oder in der Fachliteratur zirkulierte. Die Ikonografie eines „Mutterglücks“ als Teil einer Wissenskultur über „Glück“ war und ist bis heute dynamischen Umdeutungsprozessen unterworfen. Die nationalsozialistische Ikone der „deutschen“ Frau war diejenige einer „Frau als Gebärerin“43 einer Generation „neue[r] Menschen“44, wie sie Hitler bezeichnete. Entsprechend zukunftsorientiert blickt die Dreierkonstellation des ,deutschen“ „Mutterglücks“ auf ein in der Ferne liegendes Ziel. Ihre Augen fixieren das vom NS-Regime verheißungsvoll in Aussicht gestellte Versprechen einer „rassenhygienischen“ Glücksgemeinschaft.

Der Vergleich zur Schweizer Familienpolitik der „geistigen Landesverteidigung“ ist hier aufschlussreich (s. auch Kap. 14.5). Das „Mutterglück“ der „Schweizerfrau“ wird fotografisch im Frauenratgeber „Die Schweizerfrau als Mutter und Erzieherin“ (1942) von EVP-Nationalrat Hans Hoppeler (1879-1945) ${ }^{45}$ mit einer Tochter im Arm illustriert (Abb. 14). Dabei blicken sich Mutter und Tochter strahlend in die Augen.

Eine weitere Abbildung des „schweizerischen“ „Mutterglück[s]“ (Abb. 15) im selben Ratgeber zeigt in einer Farbzeichnung die kleinbürgerliche Wohnstube einer Mutter mit ihren zwei Kindern: Die schweizerische Erziehungspolitik einer „Schweizerfrau als Mutter und als Erzieherin“ wird im Titel des Ratgebers bereits programmatisch angekündigt. Gemäß einem bildungsbürgerlichen Erziehungsideal eines „schweizerischen“ „Mutterglücks“ betrachtet die Mutter in Abb. 15 gemeinsam mit ihrer Tochter bildungsbewusst ein Buch, während der kleine Bruder im Sinne der christlichen Erziehungsmoral der „geistigen Landesverteidigung“ traditionsverhaftet mit Bauklötzchen eine Kirche errichtet. ${ }^{46}$ Entsprechend dem geschlechterstereotypisierten Frauenbild der „geistigen Landesverteidigung“ wird hier eine nichtberufstätige, christliche „Schweizerfrau“ illustriert.

Die Bildunterschrift dieses häuslichen „Mutterglücks“ lautet entsprechend konservativ:

43 Hollander 1940b, 233.

44 Hitler 1935, 7.

45 Hoppeler war Mitglied der Evangelischen Volkspartei der Schweiz (EVP) und vom 01.12.1919 bis 03.12.1939 als Nationalrat tätig, https://www.parlament.ch/de/biografie/hans-hoppeler/2354, 19.08.2020.

46 Vgl. Hoppeler 1942, [3]. 


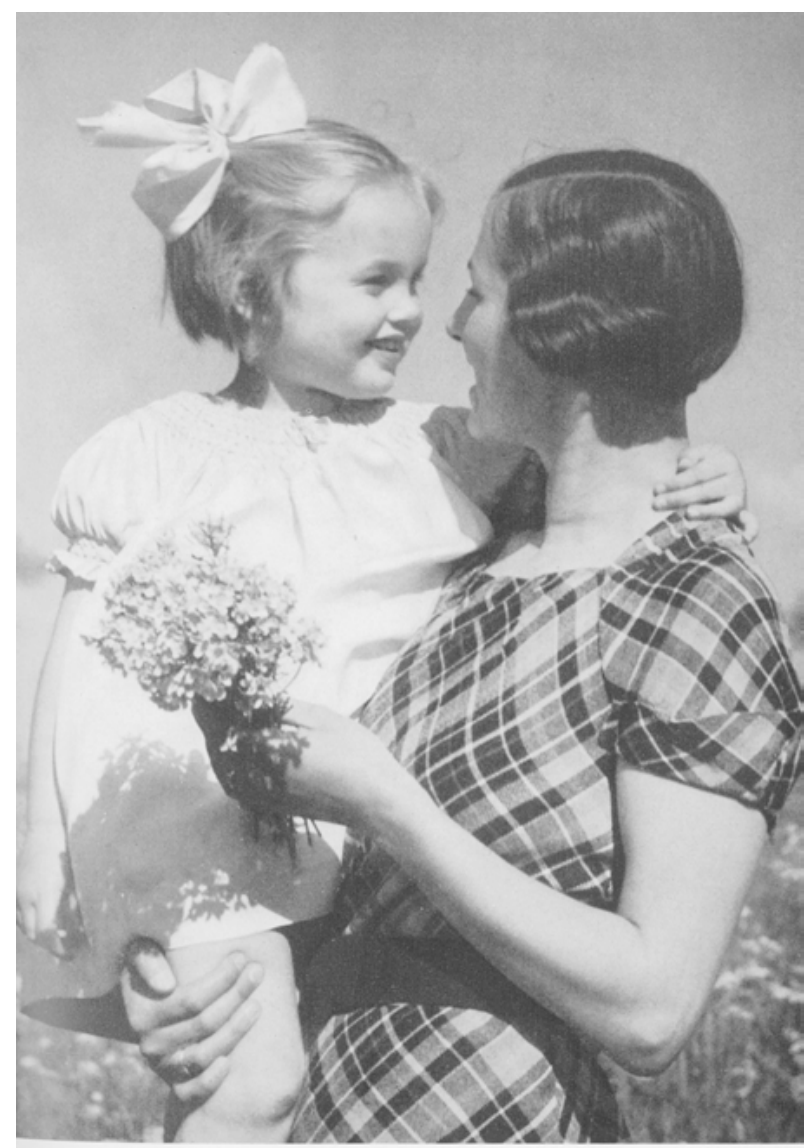

Mutterglück

Abb. 14: „Mutterglück“, Schweizer Frauenratgeber „Die Schweizerfrau als Mutter und Erzieherin“" von EVP Nationalrat Hans Hoppeler, 1943

„Mag’s dich, o Glanz der Welt, verdrießen, Ich will mein Mutterglück genießen!“47

Im transnationalen Vergleich zwischen einem illustrierten „schweizerischen“ und „,deutschen“ „Mutterglück“ fallen neben thematischen Gemeinsamkeiten auch Unterschiede auf. So weist im Fotoporträt eines „deutschen“ „Mutterglücks“

47 Ebd. 


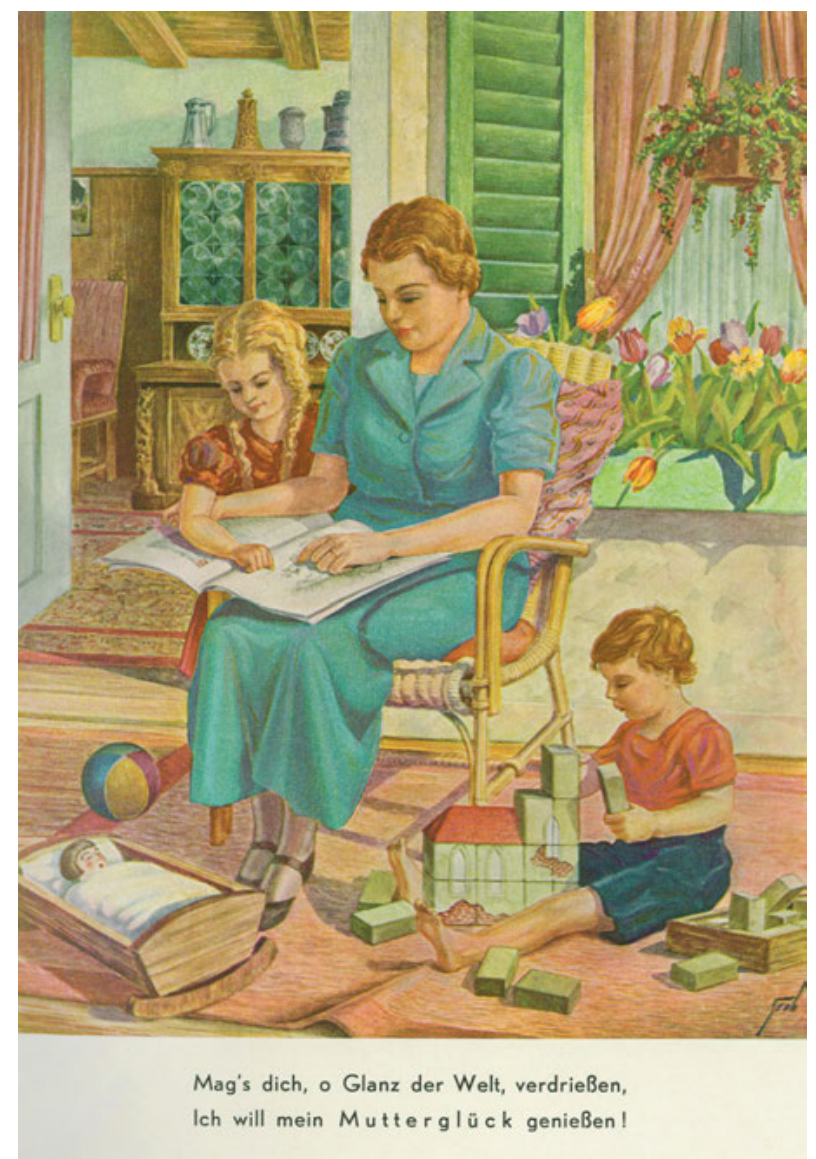

Abb. 15: „Mag’s dich, o Glanz der Welt, verdrießen / Ich will mein Mutterglück genießen!“ Schweizer Frauenratgeber „Die Schweizerfrau als Mutter und Erzieherin“ von EVP-Nationalrat Hans Hoppeler, 1943

(Abb. 13) der jüngere Sohn mit seiner linken Hand auf eine „glückliche“ Zukunft im „rassenhygienischen“ Dienst an der totalitären „Volksgemeinschaft“ hin. Beim „schweizerischen“ „Mutterglück“ liegt der Fokus auf dem gegenwartsbezogenen „Mutterglück“ als eine subjektorientierte, wechselseitig affirmative Gefühlsbeziehung zwischen Mutter und Kind.

Die „opferfreudige Liebe“, welche der Autor in seiner Doppelrolle als Ratgeber und langjähriger EVP-Nationalrat 1942 von der "Schweizerfrau“ in einem paramilitärischen Tonfall einfordert, ist in einem ambivalent humanistischen und christlich-moralisierenden Kontext der „geistigen Landesverteidigung“ verortet. 
Trotz der durchaus repressiv anmutenden Anweisung zur „hohen Pflicht“ eines „schweizerischen“ „Mutterglücks“ und einer „opferfreudigen Liebe“ stehen diese emotionspolitischen Forderungen in einer geschlechterpolitischen Diskrepanz zum „rassenhygienischen“ „Mutterglück“ der NS-Geburtenpolitik:

\begin{abstract}
„Schweizerfrau, in diesen ernsten Tagen erkenne deine hohe Pflicht! Stehe fest zu deiner Heimat und hilf ihr das Gut der Freiheit erhalten. Hilf aber vor allem ihr erhalten die Grundlage der Gerechtigkeit, der opferfreudigen Liebe und des unerschütterlichen Gottesglaubens. Denn ohne dieses Fundament sind wir verloren. Schweizerfrau, im Ringen um die äußere und innere Verteidigung der Heimat beziehe auch du deinen Posten. Sei deinem Kinde, deinem Lande Mutter und Erzieherin. “48
\end{abstract}

Die transnationale Analogie eines „Mutterglücks“ liegt folglich einer emotionspolitischen Semantik der „Opferbereitschaft“ als Dienst an „deinem Kinde, deinem Lande [als] Mutter und Erzieherin" zugrunde, die im Fall der Schweiz als eine aus patriotischer, „opferfreudiger Liebe“ entsprungene Gefühlskultur der „geistigen Landesverteidigung“ begriffen wird. Im Kriegsfall forderte sowohl die Rhetorik des „deutschen“ als auch des „,schweizerischen“ „Mutterglücks“ eine aus militärstrategischer Sicht existentielle „Opferbereitschaft“ von der Bevölkerung. Die NS-Gesellschaftsutopie nahm im Namen des NS-Regimes eine bedingungslose „Opferbereitschaft“ für „den Führer“ in Anspruch, wohingegen Hoppelers Segensspruch in den letzten Zeilen des Ratgebers „Christus“ galt:

„Er, der vom Schöpfer als höchster Erzieher dem Menschengeschlecht geschenkt ist, segne die Arbeit aller Mütter und Erzieherinnen unseres Schweizerlandes, und segne auch den Dienst, den unser Buch an ihnen ausrichten möchte.“49

Hoppeler bewertet die Lektüre des Ratgeberbuchs und die Ausübung von dessen Anleitungen als autosuggestiven Dienst am „Schweizerland [...]“, der folglich als Wissenspraktik einer exklusiv christlichen Gefühlskultur im Sinne der patriotischen Gefühlspolitik der „geistigen Landesverteidigung“ verstanden werden sollte.

Im Vergleich zur NS-Ratgeberliteratur lässt sich diese These exemplarisch veranschaulichen. Im Ratgeber „Die deutsche Mutter und ihr erstes Kind“ (1939) der Ärztin Johanna Haarer weist die Autorin im Kapitel „Die Erziehung des Kindes“ in einem ersten Schritt darauf hin, dass der Mutter die Kindererziehung schon allein aus „rassenhygienischen“ Gründen obliege: „Sie steht dem Kinde durch stärkste blutmäßige Bindung am nächsten und ist deshalb seine ihm vor-

48 Ebd., 571.

49 Ebd. 
bestimmte Erzieherin. Sie muss immer danach trachten, die Führung zu halten [...] “50 Voraussetzung für „die beste Erzieherin“ seien ihre selbstdisziplinarischen „Charaktereigenschaften und Fähigkeiten“ als Führungstypus, die ihr erst durch die emotionspolitische Erfahrung des Kindererziehens „Glück und Lebensbefriedigung“ brächten:

\begin{abstract}
„Nur eine pflichtbewusste, charakterfeste Frau mit gesundem Menschenverstand, die Sinn hat für Ordnung, Regelmäßigkeit, Pünktlichkeit und Sauberkeit wird ihr Kind richtig erziehen können. [...] Dabei ahnen sie [die kinderlosen Frauen] nicht, welch eine Fülle von Glück und Lebensbefriedigung ihnen verlorengeht, wie sie das Aufziehen gesunder Kinder mit sich bringt. “51
\end{abstract}

Als typologisches Gegenbild eines charakterologisch begründeten „Mutterglücks“ entwirft Haarer die der „NS-Rassenideologie“ zuwider handelnden „kinderlosen Frauen“, die angeblich weder dieses „Glück“ noch dieselbe „Lebensbefriedigung“ erfahren könnten.

In einem zweiten Schritt belehrt Haarer ihre Leser*innen, dass eine „deutsche Mutter“ bei aller liebevollen Fürsorge gewisse autoritäre Erziehungsregeln berücksichtigen müsse: Sie sollte nicht „,Psychologie“ an die Stelle von Erziehung“ setzen, wie es im subjektbezogenen „Jahrhundert des Kindes“ gehandhabt wurde. ${ }^{52}$ Damit spielt Haarer auf die Entwicklung der Heil- und Schulpädagogik im 19. Jahrhundert an, die exemplarisch der Schweizer Schulreformer Johann Heinrich Pestalozzi (1746-1827) vertrat und welche in der Kinder- und Erziehungspsychologie der Weimarer Zeit weiterentwickelt wurde. ${ }^{53}$ Haarers Kritik an der individualisierten Kinderpsychologie lautet:

\footnotetext{
„Damals bildete sich jener Typus von Eltern und Erziehern heraus, der über dem Beobachten und Erforschen der kindlichen Seelenregungen, also der ,Psychologie‘, die eigentliche „Erziehung “völlig vergaß und das Kind in Wirklichkeit führerlos heranwachsen ließ, oder aber, ins Gegenteil sich lehrend, aus einem Übermaß an ,Psychologisieren' heraus das Kind so unablässig gängelte, daß eine unbefangene und geradlinige seelische Entwicklung von vornherein unmöglich gemacht wurde. Diese ,schwierigen und komplizierten Kinder ‘ wurden dann aufs neue Gegenstand des unermüdlichen, ,psychologischen Interesses‘ ihrer Eltern. ${ }^{\circ 54}$
}

50 Haarer 1939, 264.

51 Ebd.

52 Vgl. ebd.

53 Vgl. ebd., $264 \mathrm{f}$.

54 Ebd., 264. 
Ein Übermaß an psychologischem Interesse seitens der Eltern an ihrem Kind und die zuweilen daraus resultierende Führungslosigkeit diskreditierte Haarer in wissenshistorischer Nähe zum Antiintellektualitätsdiskurs der auf rassistischer „Natürlichkeit“55 basierenden „NS-Rassenmoral“. Der nationalsozialistische Muttertypus wurde von Haarer als ein autoritärer Erziehungstyp konzipiert. Die „deutsche Mutter“ sollte zwar mit ihrem Kind „Sprechen“, aber „keine Nachgiebigkeit“ zeigen und ihm nicht „zu viel Bedauern“ und „zu viel Beachtung“ schenken. Zu große Aufmerksamkeit würde aus dem Nachwuchs einen „kleinen Komödianten“ machen, woraus sich „bleibende Charaktermängel“ entwickelten, argumentiert die Ärztin in Wissenskontinuität zur arbeitspsychologischen Charakterologie..$^{56}$

Das oberste Ziel der Erziehung sei es, dass sich das Kind so früh wie möglich, in die „Volksgemeinschaft“ einfüge, sodass es die „hohe[n] Erwartungen“, welche das NS-Regime an „die Jugend“ habe, erfüllen könne:

„Vorüber sind die Zeiten, wo es erstes und oberstes Ziel aller Erziehung und Aufzucht war, nur die Eigenpersönlichkeit im Kind und Menschen zu vervollkommnen und zu fördern. Eins ist heute vor allem not, nämlich[,] daß jeder junge Staatsbürger und Deutsche zum nützlichen Gliede der Volksgemeinschaft werde, daß er neben der höchstmöglichen Entwicklung all seiner guten Anlagen und Fähigkeiten lerne, sich einzuordnen in eine Gemeinschaft und um ihretwillen eigene Wünsche und eigene Bestrebungen zurückzustellen. Die erste Gemeinschaft, in die das Kind lernen muß sich einzuordnen, ist die der Geschwister. Von ihr gehen unermeßliche und unersetzliche erzieherische Werte aus. Hier wird erstmals die Forderung erhoben, auf etwas zu verzichten zugunsten anderer, und den Eigennutz zu unterdrücken zum Wohle der Brüder und Schwestern. ${ }^{\text {“57 }}$

Die Gesellschaftsutopie eines harmonischen „Mutterglücks“, das auf der Erziehungsmoral einer Ambivalenz aus Verzicht und Verwirklichung der Eigenpersönlichkeit und Wünsche basierte, sollte vom hohen Preis ablenken, welchen die Wissenspraktik der NS-Familienpolitik im Kriegsfall für das nationalsozialistische „Glück“ und die Zufriedenheit von den „deutschen“ Kindern, Müttern und Vätern fordern würde.

Zusammenfassend kann festgehalten werden, dass der „deutschen Mutter“ die Anweisung gemäß der NS-Erziehungsmoral gegeben wurde, die „Erzieherin“ ihrer Kinder zu sein, wie es zur selben Zeit von der „schweizerischen“ Mutter von

55 „Wir müssen wieder heimfinden zur Natürlichkeit, zur Reinheit und Wahrheit [...]“, schreibt die Ratgeberautorin Schilfarth 1934 bezüglich einer nationalsozialistischen „Moral“. Vgl. Schilfarth 1934, 121.

56 Vgl. Haarer 1939, 265 f.

57 Ebd., 266. 
staatlicher Seite im Sinne der „geistigen Landesverteidigung“ gefordert wurde. Doch der zusätzliche pädagogisch-propagandistische Einfluss der unterschiedlichen NS-Erziehungsanstalten („BDM“, „HJ“, „Arbeitsdienst“, „Kraft durch Freude“, „SS“ etc.), welche die Kinder im Laufe ihrer totalitären, selbsterzieherischen Lebensführung durchlaufen würden, sollte nicht unterschätzt werden. Das Familienbild eines „Mutterglücks“, wie es die „rassenhygienische“ Ausstellung „Erbgesund - Erbkrank“ propagierte, war in erster Linie jenes der gebärfreudigen „deutschen Mutter“ im „rassenhygienischen“ Dienst an der „Volksgemeinschaft“. Entsprechend lauten die letzten Zeilen von Haarers Ratgeber: „Die Mutter aber ist es, in deren Händen die glückliche Lösung aller ersten kleinen und großen Schwierigkeiten liegt. Sie hat ihr Kind unterm Herzen getragen, sie hat es geboren und genährt, sie muß es mit sanfter, aber fester Hand hineinführen ins Leben. “58 Danach übernimmt das NS-Regime die autosuggestive und emotionspolitische (Selbst-)Erziehungsarbeit.

Spätestens 1942 legte die Propagandamaschinerie die „rassenhygienische“ Bedeutung und Funktion der NS-Geburtenpolitik als eine körperpolitische und militärstrategische Gefühlskultur offen. Das „Hauptkulturamt in der Reichspropagandaleitung der NSDAP“ gab unter dem Titel „Ich kämpfe. Die Pflichten des Parteigenossen“ einen „Sonderdruck zur Erinnerung an die Aufnahme in die NSDAP“ heraus. Darin liest der „Volksgenosse“ folgende Anleitung, die dem Ratgeber „Gattenwahl. Zu ehelichem Glück und erblicher Ertüchtigung“ des „Rassenforschers“ Hans F. K. Günthers (1891-1968) oder dem oben zitierten Eheratgeber Hollanders, „Ein Leben zu Zweien“, hätte entspringen können:

„[...] Eine erbgesunde, große Familie ist höchstes Glück. Frühzeitig erwählt der Parteigenosse seine Frau nach den Grundsätzen nationalsozialistischer Rassenauslese. Hohe Kinderzahl ist ihm höchstes Glück. [...]“59

Vergleichbar erläutert Prof. Dr. Walter Groß (1904-1945), Leiter des „Rassenpolitischen Amtes“ der NSDAP, im Artikel zur „Nationalsozialistische[n] Lebensführung“60 die NS-Geburtenpolitik als NS-moralisches „Bewußtsein“ und „völkische“ Pflicht einer „rassenhygienischen“ Gefühlskultur:

„Familie und Kinder aber sind zugleich die einzige Sicherung des ewigen Lebens der Nation und darum eine Forderung der völkischen Zukunft an jeden Menschen der Gegenwart. [...] In den lebensfrohen kinderreichen Familien der nationalsozialistischen Nation findet die Verschmelzung persönlichen Lebens mit dem Dienst an der Gemeinschaft ihren überzeu-

58 Ebd., 268.

59 Hauptkulturamt in der Reichspropagandaleitung der NSDAP 1942, 95.

60 Groß 1942. 
gendsten Ausdruck. [...] Niemals aber kann von echtem Nationalsozialismus in Haltung und Gestaltung des Lebens die Rede sein, wo nicht der Wunsch nach der eigenen Familie und der großen Zahl eigener Kinder und das Bewußtsein von Glück und Pflicht zugleich vorhanden sind, die im Kinderreichtum des Volkes liegen.“61

In derselben Propagandaschrift verleiht Goebbels seinen Worten gefühls- und arbeitspolitischen Nachdruck, indem er den „rassenhygienischen“ „Kindersegen“ als „vornehmste[n] und höchste[n] Beruf einer Frau den Beruf als Frau und Mutter“ preist. ${ }^{62}$ Mit dem Dilemma der berufstätigen Frau im Kontext eines kindesreichen „Mutterglücks“ beschäftigt sich das folgende Kapitel 14.3.

\subsection{Kinderreiches „Mutterglück“: Das Dilemma der berufstätigen Frau}

„,Unsere Aufgabe heißt Arbeit, Arbeit und nochmals Arbeit.“'63 Mit diesem Zitat Hitlers beginnt der Ratgeber „Tagwerk und Feierabend. Gedanken zur Lebensführung der berufstätigen Frau“ von Else Schilfarth aus dem Jahr 1934. ${ }^{64} 1929$ hatte die promovierte Psychologin noch ein Buch über die „Psychologie der berufstätigen Frau“ verfasst. ${ }^{65} 1934$ schickt sie Hitlers affirmative NS-Arbeitsmoral der Lektüre ihres Ratgebers über die „Lebensführung der berufstätigen Frau“ voraus. ${ }^{66}$

Vor dem Hintergrund von Leys arbeitsmoralischem Grundsatz „Kraft durch Freude" können Schilfarths Ratgeberanleitungen als autosuggestive Glückspraktiken in geschlechterspezifischer Wissenskontinuität zur leistungsorientierten Arbeitspsychologie und Selbstoptimierungskultur der Weimarer Republik begriffen werden. Dies wird die folgende Analyse zeigen.

Bereits im ersten Kapitel „Beruf als Schicksal“ kommt die Ratgeberautorin der emotionspolitischen Arbeitsmoral „Kraft durch Freude“ nach, indem sie mit ei-

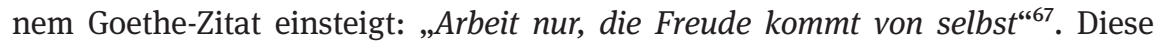
autosuggestive Anweisung habe bereits Goethe einem Besucher erwidert, als sich

61 Ebd., 62, 64.

62 „Kindersegen - das ist die Anwartschaft eines Volkes auf die Ewigkeit, deshalb ist und bleibt der vornehmste und höchste Beruf einer Frau der Beruf als Frau und Mutter“. Goebbels, zit. nach Hauptkulturamt in der Reichspropagandaleitung der NSDAP 1942, [61].

63 Hitler zit. nach Schilfarth 1934, [6].

64 Vgl. Schilfarth 1934.

65 Vgl. Schilfarth 1929 [Kursivsetzung von der Autorin ergänzt].

66 Vgl. Schilfarth 1934, [6].

67 Vgl. ebd., 7. 
dieser über seine unliebsame Arbeit beklagt habe. ${ }^{68}$ In der Wissenskontinuität über ein leistungsorientiertes Arbeitsglück im Dienst an der „Volksgemeinschaft“ leitet die Ratgeberautorin ihre Leser`innen, in Anlehnung an Goethes Bildungsroman, zum „Meisterleben“69 an. Als Praktik der nationalsozialistischen Selbstoptimierung rät sie zu einer Willensschulung und einer Technik der charakterologischen „Menschenkenntnis“, wie es auch andere Ratgeberautor`innen taten. ${ }^{70}$ Schilfarth ergänzt diese Praktiken zur „rassenhygienischen“ Selbstoptimierung durch ein nach „Feierabend“ zu gestaltendes Freizeitprogramm, das neben einer selbstdisziplinarischen Körperkultur auch Kunst, Fortbildung, Urlaub, Geselligkeit, Liebe und Freundschaft miteinschließt. ${ }^{71}$

Welchen Rat zum Erlangen eines nationalsozialistischen „Meisterleben[s]“72 gibt die Autorin einer berufstätigen Frau und welches arbeitspsychologische Glückswissen liegt dieser angeleiteten Lebensführung zugrunde? Die Ratgeberautorin hält anfangs fest: „Das große Glück“ habe „die Berufstätigkeit der Frau gebracht““73 Die zentrale Botschaft jedoch, welche der „rassenhygienische“ Frauenratgeber der berufstätigen Frau final mitteilt, ist ernüchternd: „Die Krönung der Liebessehnsucht“ sei „Gatte, Kind und Herd [...]“. ${ }^{74}$ Schilfarth entwirft in ihrem Ratgeber eine nationalsozialistische Lebensführung als weibliche Gefühlskultur eines „rassenideologisch“ überhöhten „Glücks“. Im ersten Moment eröffnet sie einen individuellen Entfaltungs- und Gestaltungsraum für die berufstätige Frau, um ihn im nächsten Moment wieder zu negieren. Ihre paradoxe Begründung dafür lautet:

„[...] das fehlte mancher Haustochter und Hausfrau von einst: die leidenschaftliche Anteilnahme an allen Lebens- und Zeitfragen, wie sie nur die Mitarbeit in der Volksgemeinschaft und die Verantwortung für die eigene Lebensführung bringen kann." ${ }^{\text {"75 }}$

Die Frauen sollten zeitlebens nicht in die „Männerarbeit einfallen und Männerwerk nachahmen. Es wird uns nie gelingen!“76 Stattdessen interpretiert die Ratgeberautorin „Werk und Meisterschaft“77 der „berufstätigen“ Frau als eine Ge-

68 Vgl. ebd., 7.

69 Ebd., 128.

70 Wie gesehen in Kap. 11-13.

71 „II. Feierabend“, vgl. Schilfarth 1934, 71-128.

72 Ebd., 128.

73 Vgl. ebd., 123.

74 Vgl. ebd., 120.

75 Ebd., $123 \mathrm{f}$.

76 Vgl. ebd., 127.

77 Ebd. 
fühlspolitik einer „liebende[n], frauliche[n], mütterliche[n]“ „Frau““ ${ }^{78}$ Ihre Lebensaufgabe bestünde darin, ihre Mitmenschen mit „Liebe“, „Arbeitsfreude und Lebenskraft“ zu erfüllen. ${ }^{79}$ Wie? Im „Dienen und Fördern“ ihrer „beglückt[en]“ Kinder, ihres Ehemannes und ihrer Mitmenschen im NS-arbeitsmoralischen Dienst an der „Volksgemeinschaft““ 80

„Frauen, deren Leben Liebe und Freundschaft ist, strahlen auf ihren Lebenskreis ein Licht und eine Wärme aus, die den trübsten Tag vergolden. Sie sind wie ein schöner Sommermorgen: heiter, klar und frisch.“" ${ }^{1}$

„Wer würde nicht beglückt in ihrem Scheine wandeln?“, fragt die Ratgeberautorin ihr Leserpublikum rhetorisch. ${ }^{82}$ Als eine „Herrschaft über die Herzen und über die Seele" versucht Schilfarth die angeblich emotionspolitische Machtstruktur, welche der nationalsozialistischen Lebensführung einer „Frau“ inhärent sein sollte, zu bewerben. ${ }^{83}$

Einer kritischen Leserin kämen nach der Lektüre des Ratgebers vielleicht Zweifel: „Oder ist es kein Glück andern Menschen Freude zu geben und eine Freude zu sein?"84 Die Ratgeberautorin antwortet mit einer emotionspolitischen Gegenfrage suggestiv: „Möchten Sie nicht diese Frau werden? Steht sie nicht in höherem Glanze, als Rang und Spitzenleistung ihn [sic] geben kann?" ${ }^{85}$ Eine Antwort auf die Frage nach der Vereinbarkeit von Beruf und Familie bleibt jeder Frau letztlich (bis heute) selber überlassen.

\section{4 „Glückliche Ehe“ dank „Eugenik“? Eine „Technik der Eheführung“ - nach 1945}

Das Wissen um ein „rassenhygienisches“ „Mutterglück“ trat nicht erst mit der Machtergreifung der Nationalsozialisten im Jahr 1933 in Erscheinung. (Populär-) wissenschaftliche Körperdiskurse um eine „eugenische“ Geburtenpolitik, die nicht nur „glückliche“ Kinder, sondern „Glück und Freude für den Einzelnen, die

\footnotetext{
78 Vgl. ebd., 122.

79 Vgl. ebd., 124.

80 Vgl. ebd.

81 Ebd.

82 Vgl. ebd., 124.

83 Vgl. ebd., 127.

84 Vgl. Schilfarth 1934, 122.

85 Vgl. ebd.
} 
Familie und die Gesamtheit“"86 brächte, zirkulierten bereits in der Weimarer Republik und wurden in ambivalenter Kontinuität in die NS-Geburtenpolitik transformiert. ${ }^{87}$ Exemplarisch dafür kann der „Lebensborn“-Ratgeber von Karl Klotz „Die neue Rasse. Ein Wegweiser zu Höherentwicklung, Glück und Freude, für den Einzelnen, die Familie und Gesamtheit“ von 1928 stehen. ${ }^{88}$ Die „Lebensborn“Bewegung wurde als Verein von der SS getragen und fand im Nationalsozialismus einen körperpolitischen Experimentierraum für „rassenhygienische“ Anwendungspraktiken. ${ }^{89}$

Das körperpolitische Wissen um ein „rassenhygienisches“ „Mutterglück“ verschwand auch nicht mit dem Ende der NS-Diktatur, wie man annehmen könnte. Dies zeigt exemplarisch die folgende Analyse der Ausgaben von Hollanders Ratgeber „Ein Leben zu Zweien. Ein Ehebuch, Betrachtungen und Geschichte“. Hollanders Eheratgeber erschien 1940 und wurde 1955 und 1961 neu aufgelegt. ${ }^{90}$ Die vergleichende Analyse der drei Ausgaben lässt neben inhaltlichen Brüchen insbesondere in Bezug auf das Glückswissen einer „rassenhygienischen“ NS-Geburtenpraktik auch Kontinuitäten erkennen.

Im neu hinzugefügten „Vorwort“ der Auflage von 1955 erwähnt Hollander erstaunlicherweise im Kapitel „Was sich änderte“ nicht als Erstes den rechtsstaatlichen Umbruch der demokratischen Familienpolitik in der BRD nach dem Ende der NS-Diktatur. Er schreibt:

„Die erste Ausgabe dieses Buches erschien im Jahr 1940. Sie brachte mir einen großen Erfolg ein - und sehr viel Arbeit. Denn seitdem mußte ich viele Tausende von Briefen lesen und beantworten, in denen mich Eheleute und solche, die es werden wollten, um Rat fragten. Ich habe diese Arbeit gern getan. Vor allem weil ich in manchen Fällen tatsächlich helfen konnte. [...] Ich konnte auch erfahren, was sich allmählich änderte und was unverändert blieb. [...] Geändert haben sich in erster Linie die Frauen. Sie sind selbständiger geworden. Vor allem in ihrem Handeln. [...]“91

86 Vgl. Klotz 1928.

87 Zur ambivalenten Kontinuität der „eugenischen“ Geburten-, Familien-, Frauen- und Erziehungsdiskurse in der Medizin, Ratgeberliteratur und bürgerlichen Gesellschaft der Weimarer Republik vgl. Manz 2007, Wecker 2009, Maubach 2018, Freimüller 2018, Kravetz 2019.

88 Vgl. Klotz 1928.

$89 \mathrm{Zu}$ „Lebensborn“ vgl. Clay und Leapman 1995, Lilienthal 2003.

90 Vgl. Hollander 1940b, vgl. Hollander 1955, vgl. Hollander 1961. Lu Seegers konnte anhand Walter Hollanders ungebrochener Karriere als Ratgeberautor und Rundfunkmoderator von der Weimarer Zeit bis in die Nachkriegszeit aufzeigen, welche gesellschaftsrelevante Bedeutung Ratgeberwissen, insbesondere in Bezug auf eine individuelle Paar- und Ehetherapie, unabhängig von politischen Systemwechseln zukommen konnte.

91 Hollander 1955, 9. 
Als größte gesellschaftliche Veränderung der Nachkriegszeit führt Hollander die angeblich verbesserte soziale Stellung und demokratisch-selbstbestimmtere Handlungsmöglichkeit „der Frauen“ an, gefolgt vom größeren Erfahrungsschatz „sexuelle[r] Erlebnisse“ in vor- und außerehelichen Beziehungen. ${ }^{92}$ Paradoxerweise war es der Ratgeberautor selbst, der noch in der NS-Zeit auf der Grundlage seines „rassenhygienischen“ Ratgeberwissens „die Frau“ ihrer sozialen Stellung und Handlungsmöglichkeit beraubte, indem er sie bevorzugt zur leistungsorientierten Geburtenpraktik animierte und sie damit biologistisch zur unfreiwilligen Berufsunfähigkeit degradierte.

Im demokratischen Verständnis einer Eheschließung lehnt er es nach $1955 \mathrm{ab}$, dass „die Ehe durch bestimmte Gesetze geschützt, von Staates wegen erhalten, von oben her geordnet werden müsse“. ${ }^{93}$ Stattdessen betont er die psychotechnische Wissenskontinuität seiner bereits 1940 unter dem Schlagwort „Menschenerziehung statt Ehereform“94 angeleitete „Technik der Eheführung“"95:

\begin{abstract}
„Wir wollen keine Ehereform vorschlagen, sondern vielmehr zu erweisen trachten, daß im gegebenen Ehebereich für jeden Menschen von heute (oder doch für fast jeden) genügend Lebensmöglichkeiten bestehen, sofern er sich selbst erziehen und entwickeln will. Freilich besagt das gleichzeitig, daß die meisten Menschen weit unter der Ebene ihrer Möglichkeiten leben und daß nur dann im Bereich der Ehe glückliche Möglichkeiten bestehen, wenn man gewillt ist, an sich selbst genügend zu arbeiten.“96
\end{abstract}

In wissenshistorischer Kontinuität zur leistungsorientierten Rationalisierungskultur der Weimarer Republik lehrt Hollander seine Ratsuchenden, dass sich (,fast“) jede Frau und jeder Mann in selbstdisziplinarischer und psychotechnischer Praktik weiterentwickeln könne, wenn der entsprechende Wille vorhanden sei. Hollander verfolgte mit seiner „Technik der Eheführung“ sowohl im Nationalsozialismus als auch in der BRD dasselbe übergeordnete Ziel:

„,Das Leben zu Zweien“ wurde in der Überzeugung geschrieben, daß man [...] Grundfehler vermeiden kann und daß man die Ehe erlernen muß, genauso wie man alle anderen Dinge des Lebens erlernt. [...] Ich habe aber auch versucht zu beschreiben, wieviele ungehobene Glücksmöglichkeiten in fast jeder Ehe liegen, wenn man nur ein bißchen objektiv ist gegen sich selbst, wenn man den Partner in seiner Eigenart achtet, in seiner Besonderheit wachsen läßt und - wenn man ein bißchen Humor aufbringt."“77

92 Vgl. ebd.

93 Vgl. ebd., 10.

94 Vgl. Hollander 1940b, 22f.

95 Hollander 1955, 11.

96 Hollander 1940b, 22.

97 Hollander 1955, 11. Ähnlicher Wortlaut in der Erstausgabe von 1940, vgl. Hollander 1940b, 22. 
Hollanders einzige Forderung an seine Ratsuchenden in der Auflage von 1955 sei „Selbstkritik“, denn moralische Dogmen würden die Menschen überfordern. ${ }^{98}$ Dabei verweist Hollander auf den Neurologen und „Rassenhygieniker“ Viktor von Weizsäcker (1886-1957) und dessen Behauptung: „Die bürgerliche Ordnung und die praktische Moral erweisen sich als undurchführbar, mindestens: sie werden nicht durchgeführt. “99 In Anbetracht der antisemitischen „NS-Rassenpolitik“ und der damit verbundenen „rassenhygienischen“ NS-Geburtenpolitik mag die Referenz im Jahr 1955 auf einen in die „Euthanasie“-Praktiken des NS-Regimes verstrickten Mediziner erstaunen. ${ }^{100}$ Hollander begreift seinen Eheratgeber von 1955 , wie schon 1940, als einen Wegweiser zu einer „neuen Moral, zu einer neuen Form der Ehe“, mit dem Unterschied, dass der paradoxen Forderung nach einer Moral nicht länger eine „NS-Rassenmoral“ zugrunde liegt. ${ }^{101}$ Für die Neuausgabe von 1955 arbeitete Hollander das Kapitel „Das Glück, Kinder zu haben“ grundlegend um. Seine NS-ideologische Legitimation des „Euthanasiegesetztes“ sowie die Ratgeberanleitung zur „rassenhygienischen“ Lebensführung fehlen. ${ }^{102}$ In den Ausgaben von 1955 und 1961 erfährt die Glückswissenspraktik der von Hollander beworbenen Familienpolitik jedoch einen ambivalenten Deutungswandel.

Im Kapitel „Kann es eine Eugenik geben?“ distanziert sich der Ratgeberautor zunächst von Hitlers „NS-Rassenpolitik“, um gleichzeitig sein ungebrochenes „eugenisches“ Gedankengut preiszugeben:

„Die Eugenik, die sich mit diesen Fragen beschäftigt, die viel an den Erbströmen herumforschte und sich wenig mit der rechten Art und der rechten Zeit der Zeugung beschäftigte, hat brauchbare Ergebnisse für den einzelnen Menschen noch nicht hervorgebracht. Außerdem ist sie durch die vorschnellen und schon deshalb gefährlich falschen Gesetze des völlig ungebildeten Hitler so in Verruf geraten, daß niemand mehr ihr traut, ja, daß fast niemand sich traut, auch die einfachsten Erkenntnisse ins Werk zu setzen, die Erkenntnis zum Beispiel, daß wahrscheinlich bestimmte Menschengruppen doch verhindert werden müßten, Kinder zu bekommen." ${ }^{103}$

Hollanders rassistischer Vorschlag war, eine „eugenische“ Körperkultur in bildungsbürgerlicher Wissenskontinuität, im Gegensatz zum angeblich ,völlig un-

98 Vgl. Hollander 1955, 11.

99 Viktor von Weizsäcker zit. nach Hollander 1955.

100 Zur Biografie vgl. Benzenhöfer 2007.

101 Vgl. Hollander 1955, [Klappentext].

102 In der ersten Ausgabe war das Kapitel „Das Glück, Kinder zu haben“ in die Unterkapitel „1. Keine Kinder - halbes Leben“, „2. Der materielle Einsatz“, „3. Kinder bringen Glück“, „4. Grenzen der Erziehung“, „5. Erneuerung in den Kindern“ „6. Schönheit der kinderreichen Frau“ aufgeteilt. 103 Hollander 1955, 117. 
gebildete[n] Hitler“, in der demokratischen BRD fortzusetzen. Auf diese Weise sollte die „in Verruf geraten[e]“ „Eugenik“ bereits zehn Jahre nach Kriegsende wieder diskursfähig gemacht werden.

Ein weiteres Beispiel für eine Publikationskontinuität eines Ratgebers, der „rassenhygienisches“ Glückswissen nicht nur während der NS-Zeit veröffentlichte, sondern in dritter, „umgearbeiteter“ Auflage auch noch 1951 verbreitete, ist der Ratgeber „Gattenwahl. Zu ehelichem Glück und erblicher Ertüchtigung“ des „Rassenforschers“ Hans F. K. Günther. ${ }^{104} \mathrm{Zu}$ seinen einschlägigsten Büchern zählt „Rassenkunde des deutschen Volkes“, das bereits 1922 in der Weimarer Republik erschienen war. ${ }^{105}$

Mit ihrer biologistischen Einstellung gegenüber einer „eugenischen“ Körperpolitik standen die Ratgeberautoren Hollander und Günther in der Nachkriegszeit nicht alleine da, was der Blick ins Nachbarland Schweiz und dessen Sterilisationspraktik im Rahmen der demokratischen Sozialpolitik beweist. ${ }^{106}$

\subsection{Das „Mutterglück“ der Schweizerfrau und ihr Geheimnis einer ,gesunden und glücklichen Ehe“"}

In diesem Kapitel soll das „Mutterglück“ der „Schweizerfrau als Mutter und Erzieherin“ und ihr „Geheimnis einer gesunden und glücklichen Ehe“ im Ratgeber von Hans Hoppeler aus dem Jahr 1942 exemplarisch in einen transnationalen Vergleich mit dem der „deutschen Frau“ in Hollanders Ratgeber „Ein Leben zu Zweien“ von 1940 gestellt werden. Der Ratgeber „Die Schweizerfrau als Mutter und Erzieherin“ des ehemaligen EVP-Nationalrats und Mediziners Hans Hoppeler war in Zusammenarbeit mit der Schweizerischen Mütterschule „Pro Infante“ 1942 erschienen und wurde noch 1950 in 7. Auflage gedruckt: ${ }^{107}$

„Mütter, Erzieherinnen! [...] Schweizerfrau, in diesen ernsten Tagen erkenne deine hohe Pflicht! Stehe fest zu deiner Heimat und hilf ihr das Gut der Freiheit erhalten. Hilf aber vor allem ihr erhalten die Grundlage der Gerechtigkeit, der opferfreudigen Liebe und des unerschütterlichen Gottesglaubens. Denn ohne dieses Fundament sind wir verloren.

104 Vgl. Günther 1951. Zur Biografie, biografische Angaben in „Kalliope-Verbund“, http://kalli ope-verbund.info/de/eac?eac.id=118698923, 12.09.2020.

105 Vgl. Günther 1922.

106 Zur „Kastration“, „Sterilisation“ und „Rassenhygiene“ in der Schweizer Sozialpolitik, Verhütungspolitik, Psychiatrie und Heilpädagogik, 1900-1970, vgl. Günther 1951, Huonker 2003, Wecker 2009, Dubach 2013, Wecker und Küchenhoff 2013, Germann 2016.

107 Vgl. Hoppeler 1942. 
Schweizerfrau, im Ringen um die äußere und innere Verteidigung der Heimat beziehe auch du deinen Posten. Sei deinem Kinde, deinem Lande Mutter und Erzieherin!“"108

In einer „opferfreudigen Liebe“ und im „unerschütterlichen Gottesglauben“ sollte sich die „Schweizerfrau“ in ihrer Doppelrolle als „tüchtige“ „Mutter“, „Erzieherin“ und Patriotin im Kriegsalltag beweisen. Die Leistungsfähigkeit der „Schweizerfrau" wird im Vergleich zum NS-Mutterkult auch in der Familienpolitik der „geistigen Landesverteidigung“ betont. Ihre Leistungsfähigkeit als Mutter wird nach christlichen Moralvorstellungen als eine pflichtbewusste Opferfreudigkeit bewertet. Trotz semantischer Analogie entspringt sie jedoch keiner vergleichbar „rassenhygienischen“ Körperpolitik, wie sie im Nationalsozialismus intendiert war.

Wie ambivalent die Doppelrolle einer zeitgenössischen Geschlechterstereotypisierung der „Mutter“ und „Erzieherin“ transnational gedeutet wurde, zeigt das Vorwort des Verfassers. Hoppeler, Kinderarzt und jahrelanger Leiter eines Kinderheims sowie „Vater einer Kinderschar“ betont in seiner Einführung, dass er keine „fertigen Regeln“ präsentieren, sondern „unsere[n] Leserinnen selbständig denken lernen“ beibringen wolle:

„[...] daß sie [unsere Leserinnen] die Fundamente kennen lernen, welche jeder guten Pflege und gewissenhaften Erziehung zu Grunde liegen, und daß sie dann von solcher soliden Grundlage aus zu jeder Einzelfrage und zu jeder einzelnen Situation und Schwierigkeit aus eigenem Denken und Empfindung heraus Stellung zu nehmen im Stande sind. Die auf Grund gesunden Fundamentes und klaren Zieles selbständig denkende und selbständig handelnde Mutter: das ist, was wir erreichen möchten. Eine Mutter, die nicht von allen möglichen Ratschlägen der Freundinnen und guter Nachbarinnen oder von guten und schlechten pädagogischen Aufsätzen, politischer oder familiärer Zeitschriften abhängig ist, sondern eine Mutter die ihren Weg kennt, und die in allen wichtigen Fragen weiß worauf es ankommt. " ${ }^{109}$

Natürlich steckt auch in Hoppelers Rhetorik der „selbständig denkende[n] und selbständig handelnde[n] Mutter“ eine ambivalente Wissenspraktik. Die Anleitungen des ehemaligen Nationalrats und Mitglieds der EVP sind nicht wertfrei, sondern im Kontext der nationalistischen Familienpolitik der „geistigen Landesverteidigung“ verfasst. Dennoch ist auffällig, wie seine rhetorische Einführung vordergründig nicht top down, als hegemonialer Erziehungsdiskurs auftreten möchte. Die Leser`innen sollten autopädagogisch (bottom up) zum selbständigen Handeln anregt werden. Der Mutter-Typus sollte sich ein eigenes Urteil über die

108 Ebd., 571.

109 Hoppeler 1942, $6 \mathrm{f}$. 
Methoden bilden, die ihr im Ratgeber vorgeschlagen würden. Hoppeler nennt seinen Ratgeber daher auch eine „Psychologie für Mütter“, um eine „umfassende Kenntnis der Kindesseele“ zu erlangen. ${ }^{110}$ Das Ziel des Ratgebers sei es aufzuzeigen:

„[...] wie eines Kindes Verstandesgaben durch zielbewußte Leitung der Erzieher zur vollen Entfaltung gebracht werden können. Vor allem aber möchte es die rechten Wege aufweisen, den Charakter des Kinders so zu gestalten, daß Wahrheit, Pflichterfüllung und Reinheit in ihm eine unverbrüchliche Stätte haben, und daß der Geist in ihm wohnt, der von oben kommt und nach oben führt!"111

Hoppelers charakterologische Wortwahl erinnert zunächst an C.H. Huters PsychoPhysiognomische Lehre sowie Schilfarths und Rinnes Wege zur „Lebensmeisterung“. Im Unterschied zur „Selbstmeisterung“ durch „Menschenkenntnis“ schlägt Hoppeler jedoch eine psychologische Erziehung vor, die den „Charakter des Kindes“ hinsichtlich „Wahrheit, Pflichterfüllung und Reinheit“ schulen solle. ${ }^{112}$ Anders als Haarer steht Hoppeler in der Wissenskontinuität des ,,Jahrhundert[s] des Kindes“" und scheint einer psychologischen Kindererziehung, die individualtherapeutisch auf den Charakter des Kindes einwirke, nicht abgeneigt. Dennoch benennt Hoppeler moralische Erziehungswerte wie „Wahrheit“, „Pflichterfüllung“ und „Reinheit“, die er dogmatisch den Leser^innen zu lehren beabsichtigt.

Welche wissenshistorische Bedeutung kommen den pädagogischen Begrifflichkeiten („,Wahrheit“, „Pflichterfüllung“ und „Reinheit“) bei Hoppeler zu und in welchem Zusammenhang stehen sie zu seinem Glückswissen? Unter dem Leitgedanken „Wahrheit“ erklärt Hoppeler gleich zu Beginn seines Ratgebers „Das Geheimnis der gesunden und glücklichen Ehe“ ${ }^{113}$ Er sieht drei aktuelle „Hauptursachen des heutigen Ehe-Zerfalls“. ${ }^{114}$ Diese wären 1. die rege genutzte Möglichkeit zur Scheidung und folglich hohe Scheidungsrate, 2. ein „Mangel“ an Gemeinschaftsgefühl, „Opferwilligkeit“ sowie „hingebender und dienender Liebe“ und 3. ein „Schwinden des Gottesglaubens, und damit die Trennung der Ehe vom ewigen Gott“ ${ }^{115}$ Als gläubiger Christ lauten seine Leitsätze für eine „glückliche Ehe“ folgendermaßen:

110 Vgl. ebd., 7.

111 Ebd.

112 Vgl. ebd.

113 Gleichnamiges Kapitel, vgl. ebd., 10-14.

114 Ebd., 7.

115 Vgl. ebd., 11. 
„[...] fester Wille zur Treue bis in den Tod in der nach Gottes Willen unauflöslichen Ehe; fester Wille zu tapferer Zurückbindung des eigenen anspruchsvollen Ich [sic]; und fester Wille endlich, die Gemeinschaft mit Gott aufrecht zu erhalten, um durch sie steten Zustrom von Kräften der Opferfreudigkeit und der Liebe zu erbitten."“116

Hoppeler appelliert an eine auf christlichen Glaubensätzen basierende „Opferfreudigkeit“ aus „dienender Liebe“ der „Frau“, unter „Zurückbindung des eigenen anspruchsvollen Ichs“, zum Wohle der „Gemeinschaft“"117 innerhalb einer patriarchalen Familienstruktur:

„Der Mann sei das Haupt. So verlange es Gott in der Heiligen Schrift. Aber auch das andere ist göttliche Vorschrift: Ihr Männer, liebet eure Weiber mehr als euch selbst! Wo das befolgt wird, da ist wohl der Mann der führende Teil, aber niemals im Sinne harter Regentschaft, sondern als einer der alle wichtigen Fragen der Hauswirtschaft und der Erziehung mit seiner Frau kameradschaftlich bespricht, und seinen Willen nur da dem ihr eigenen voransetzt, wo seine Ueberzeugung und sein Gewissen dies verlangen.“118

Hoppeler entwirft in seiner dichotomen Geschlechtervorstellung von einer „gesunden und glücklichen Ehe“ kein selbstbestimmtes Frauenbild, wie er es rhetorisch im Vorwort noch angepriesen hat. Er bezeichnet „Ehefrauen“ und angeblich achtbare „Mütter“ pejorativ als „Weiber“. An erster Stelle stünde in der Familienhierarchie „der Mann“, der sich „kameradschaftlich“ mit „seiner Frau“ lediglich über „Hauswirtschaft“ und Kindererziehung absprechen müsse und selbst in diesen Bereichen aus moralischen Gründen das letzte Wort habe. Darin läge die „Wahrheit“ einer „glücklichen Ehe“, womit sich Hoppeler an das Eherecht des Schweizer Zivilgesetzbuchs von 1907 anlehnt. ${ }^{119}$

Die Ähnlichkeit mit dem bereits untersuchten Geschlechterbild der „deutschen Frau“ hinsichtlich ihrer Aufgabe, als „dienende“, „opferfreudige“ und „liebende“ „Mutter“ und „Erzieherin“ zum Wohl der „Gemeinschaft“ als „höchste[m] Beruf“ in einer patriarchalen Familienstruktur wirken zu dürfen, ist auffällig. ${ }^{120}$

Emanzipierte Psycholog^innen wie Franziska Baumgarten waren anderer Auffassung, wie die exemplarische Analyse ihres Ratgebers „Beratung in Lebenskonflikten“ zeigen soll. Baumgartens Ratgeber ist ein Resümee ihrer

116 Ebd., 12.

117 Ebd., 11.

118 Ebd., 12.

119 Zum Schweizer Eherecht s. später in Kap. 14.5.

120 Eine weiterführende Untersuchung zu Hoppelers Schriften diesbezüglich wäre erkenntnisreich. 
langjährigen Erfahrung als Psychologin mit unterschiedlichen biografischen Narrativen von „,bedrückende[n] Lebenssituationen“. ${ }^{121}$ Obwohl sie keine psychiatrische Praxis betrieb, wandten sich viele Ratsuchende an die lebenserfahrene Professorin für Arbeitspsychologie. Ein Großteil ihrer Beratung konzentrierte sich auf „Eheprobleme“, mit denen sich hauptsächlich Frauen an die Psychologin wandten. ${ }^{122}$ Das Ziel ihres Ratgebers war es, anhand der Fallbeispiele aufzuzeigen, wie komplex sich das „Zusammenleben unter Menschen“ gestalte, wie „schlimm es in der heutigen Zeit um die Charakterbildung bestellt“ sei und wie oft den Menschen, die in ihren Nöten allein gelassen werden, geholfen werden könne. ${ }^{123}$ „Möge daher dieses Büchlein den Weg nicht nur zu einem breiteren Publikum, sondern speziell auch in Erzieherkreise finden“, lautet die Intention der Autorin. ${ }^{124}$ Ihre Begegnungen mit Ratsuchenden, „Freunden und Bekannten, aber auch Fernstehenden und Unbekannten, mündlich und schriftlich mit der Bitte um Beratung an mich gewandt“, sind in Dialogform wiedergegeben. ${ }^{125}$ Die biografischen Erzählungen präsentieren sich der Leserschaft in einer Art psychologischem Therapiegespräch, worüber eine auktoriale Erzählposition im Rückblick berichtet.

Wie lauten Baumgartens Anleitungen zu Arbeitsglück, Eheglück und/oder Mutterglück aus der Frauenperspektive? Baumgarten rät ihren Klient*innen, sich nicht von gesellschaftlichen Normen vorschreiben zu lassen, wie sie ihr Leben zu führen hätten. Nicht die „sogenannte[...] Gesellschaft“126 würde wissen, wie ihr „persönliches Glück[...]“127 auszusehen habe. Jede Frau müsse gemäß ihrer „Eigenart“128 darüber entscheiden, worin ihr „Glück“ liege, auch wenn dies zuweilen bedeute, soziale Brüche in Kauf zu nehmen. Am Ende sei der Weg der kritischen Selbsterkenntnis und charakterologischen Menschenkenntnis der einzige, um Erfolg im Leben und „Glück“ erfahren zu können. ${ }^{129}$

Die Erzählungen geben der Arbeitspsychologin Recht: Die von der Ratgeberautorin ausgewählten Biografien enden ausnahmslos im ,Happy End‘. Gemäß

121 „Im Laufe der Jahre bildete sich ein umfangreiches Material, das mir wert schien, wenigstens teilweise veröffentlicht zu werden. (Natürlich wurden dabei ausschließlich diejenigen Fälle berücksichtigt, deren Problematik für die beteiligten Personen nur mehr , historischen Wert‘ besaß, die näheren Umstände wurden unkenntlich gemacht.)“. Vgl. Baumgarten 1943, 7.

122 Vgl. Baumgarten 1943, 8.

123 Vgl. ebd.

124 Vgl. ebd.

125 Vgl. ebd., 7.

126 Ebd., 27.

127 Ebd., 61.

128 Ebd., 61.

129 Vgl. ebd., 7. 
ihrer psychotechnischen Erfolgs-Dramaturgie lautet Baumgartens Anweisung, eine selbstbestimmte Lebensführung entsprechend der eigenen, charakterologischen Eigenschaften zu wählen, um „persönliches Glück[...]“130 $\mathrm{zu}$ finden. Die Titelvergabe der jeweiligen Lebensbiografien („Der Haustyrann“, „Die Altruistin“, „Die servile Gattin“, „Der Asoziale“, „Der Menschenhasser“, „Der Neider“, „Die Wahrheitsfanatikerin“) entlarvt jenen verhängnisvollen psychologischen Charakteranteil, der ihren Klient*innen bisher ein „glückliches“ Leben verunmöglicht habe.

Ein Beispiel soll Baumgartens Anleitungen zu einer selbstbestimmten Lebensführung und „persönliche[m] Glück[...]"131 vor dem Hintergrund der Familienpolitik der „geistigen Landesverteidigung“ während des Zweiten Weltkriegs sowie der arbeitspsychologischen Forschung der Professorin veranschaulichen. Das Beispiel erzählt von einer vermeintlich „moderne[n] Mésalliance“ zwischen einer gut situierten Kinderärztin und ihrem mittellosen, dafür moralisch integer handelndem Liebhaber und späterem Ehemann. Die Erzählung der Kinderärztin steht exemplarisch für Baumgartens Bewertungskonzept über persönlichen „Erfolg“ und „Glück“. In der ersten „Partnerbeziehung“ mit dem dominanten, dafür sozial anerkannten Mediziner war das „nach Anerkennung strebende[...] Ich“ der Kinderärztin, die zu seiner Praxisassistentin degradiert wurde, zu kurz gekommen. In ihrer zweiten Beziehung erfuhr sie die „Anerkennung“ ihres „Ich’s“ als selbständig erwerbende Ärztin von ihrem Ehemann, dem „die Anerkennung spendenden Du“. Ihrem Ehemann sollte sie, laut Baumgartens „Erfolgs“-Konzept, wiederum dieselbe „Anerkennung“ geben, die er für seine charakterlich wertvolle „Leistung“132 in der Beziehung zu ihr tagtäglich erbrachte. Ob Arbeitsglück, Eheglück oder Mutterglück - der private und berufliche „Erfolg“ sei danach zu bewerten, ob dieser der charakterologischen Eigenschaft entspräche, und nicht, ob dieser dem hegemonial geführten Moraldiskurs bzw. einer eherechtlichen Definition entspräche, die vorgab zu wissen, was eine, normale، Ehe sei und wie „Eheglück“ emotionspolitisch gelebt werden müsse. Vor diesem Hintergrund sollen Baumgartens Anleitungen innerhalb der Geschichte des Schweizer Frauenrechts verortet werden.

130 Ebd., 61.

131 Ebd., 61.

132 Baumgarten schreibt zur ambivalenten „Anerkennung“ von „Erfolg“ in arbeitsmoralischer Relation zur charakterologischen „Leistung“ des „Leistenden“: „Mancher Erfolg wird sich als leerer oder böser Wahn erweisen. Der Glanz manches Erfolges wird durch die Feststellung seiner trüben Quellen verdunkelt werden. Um so mehr wird ein Erfolg leuchten, dessen reine Quellen erkennbar sind.“ Vgl. Baumgarten-Tramer 1942, 443. 
Die rechtliche Situation der Frauen in der Schweiz hat sich erst seit den 1970er Jahren verbessert, als Bürger^innen das Stimm- und Wahlrecht erhielten. 1981 wurde der „Grundsatz der Gleichbehandlung“ in die Bundesverfassung aufgenommen:

„Mann und Frau sind gleichberechtigt. Das Gesetz sorgt für ihre rechtliche und tatsächliche Gleichstellung, vor allem in Familie, Ausbildung und Arbeit. Mann und Frau haben Anspruch auf gleichen Lohn für gleichwertige Arbeit. “133

Doch erst am 1. Juli 1996 trat das Schweizerische Bundesgesetz über die Gleichstellung von Mann und Frau in Kraft. Dieses verbietet die Diskriminierung im Erwerbsleben und schlägt Maßnahmen vor, um die Chancengleichheit im Berufsleben zu erleichtern. ${ }^{134}$ Der zweite „Frauenstreik 2019“135 hat gezeigt, dass immer noch „großer Handlungsbedarf“ in der „tatsächlichen Gleichstellung“ besteht, wie die „Eidgenössische Kommission für Frauenfragen“ auf ihrer Webseite einräumt:

„Die stereotypen Rollenvorstellungen beginnen sich zwar langsam aufzuweichen, doch in Wirtschaft, Wissenschaft, Verwaltung, Politik und Öffentlichkeit sind Frauen noch immer nicht gleich vertreten und besetzen deutlich weniger einflussreiche Positionen als Männer. Umgekehrt leisten Frauen weiterhin den grössten Teil der unbezahlten Arbeit in Haushalt und Familie. Auch hier sind unter anderem gesetzgeberische Schritte gefragt, um die nötigen Rahmenbedingungen für die wirtschaftliche und soziale Chancengleichheit der Geschlechter zu schaffen." ${ }^{136}$

Vor diesem kurzen Abriss einer Geschichte der Frauenrechte in der Schweiz sind die Anleitungen, welche die Professorin für Arbeitspsychologie ihren Klient*innen gab, wenn diese ihr die geschlechterpolitisch brisante Frage nach der Vereinbarkeit von Berufstätigkeit, Ehe, Mutterschaft und einem „glückliche[n] Leben“137 stellten, als progressiv zu bewerten.

133 Bundesverfassung der Schweizerischen Eidgenossenschaft, Art. 8 Abs. 3. „Rechtsgleichheit“, https://www.admin.ch/opc/de/classified-compilation/19995395/index.html\#a8, 01.12.2020.

134 Vgl. Bundesgesetz über die Gleichstellung von Mann und Frau (Gleichstellungsgesetzt, GIG) vom 24. März 1995, https://www.admin.ch/opc/de/classified-compilation/19950082/index.html, 01.12.2020.

135 Zum Frauenstreik 2019, https://www.ekf.admin.ch/ekf/de/home/themen/frauen-und-gleich stellung-allgemein/frauenstreik2019.html, 01.12.2020.

$136 \mathrm{Zu}$ „Frauen und Gleichstellung. Allgemein“, Eidgenössische Kommission für Frauenfragen (EKF), https://www.ekf.admin.ch/ekf/de/home/themen/frauen-und-gleichstellung-all gemein.html, 01.12.2020.

137 Baumgarten 1943, 29. 
Vor einem ambivalenten geschlechterhistorischen Wissenskontext während des Zweiten Weltkriegs ist dann auch die zweite Forderung Hoppelers, die Erziehung zur „[t]reue[n] Pflichterfüllung als Frucht der Selbstbeherrschung“ zu verorten. Hoppeler rät seinen Leser^innen „nicht nur, das zu lassen, was man gerne täte, und doch nicht tun sollte; sondern auch: das tun, was man nicht gerne tut, und doch zu tun verpflichtet wäre. “138 Kinder und Erwachsene sollten daher in Selbstüberwindung geschult werden, um der „gewissenhaften Erfüllung [ihrer] Pflichten“ nachzukommen. ${ }^{139}$ Ziel einer strengen und unnachgiebigen Erziehung sei es, das Kind in seiner „Kraft“ zu stählen, sodass es später durch eine „straffe[...] Erziehungsschule“ und unter „herbe[r] Willensanstrengung und aufopfernde[r] Selbstüberwindung“ „Selbstbeherrschung“ gelernt habe, um der „Pflichterfüllung“ nachzukommen. ${ }^{140}$

Als Beispiel seines ambivalent autoritären und zugleich autosuggestiv praktizierbaren Erziehungsstils nennt Hoppeler das „Haus-Aemtlein“141, aber auch moralische Umgangsformen wie die „Erziehung zur Dankbarkeit“142, hygienische Körperpraktiken wie „Reinlichkeit“"143, gesellschaftliche Verhaltensnormen wie „Ordnungs-Sinn“144, „Pünktlichkeit“145, „Ausdauer und Geduld“146 sowie charakterliche Tugenden wie „Friedensliebe und Persönlichkeit“147, „Bescheidenheit“148 und „Zuverlässigkeit“149. Die „Erziehungsziele“ fasst Hoppeler in fünf „Tugenden“ zusammen: „Gehorsam“, „Wahrhaftigkeit“, „Nächstenliebe“, „Pflichterfüllung“ und „sittliche Reinheit““. ${ }^{150}$ Unter „sittlicher Reinheit“ wird im Kontext der „geistigen Landesverteidigung“ keine „rassenhygienische“ Reinheit postuliert. Hoppeler versucht, die Pubertierenden vor einer vorehelichen Schwangerschaft zu schützen.

Welches Erziehungswissen gab der Glücksratgeber Hollander im transnationalen Vergleich seinen Leser`innen mit auf den Weg? Ein „Mutterglück“ käme nie allein, so Hollander, sondern bringe auch immer ein ambivalentes Gefühlskon-

138 Vgl. Hoppeler 1942, 387.

139 Vgl. ebd., 387.

140 Vgl. ebd., 388.

141 Vgl. ebd., $388 \mathrm{ff}$.

142 Vgl. ebd., $391 \mathrm{f}$.

143 Vgl. ebd., $393 \mathrm{ff}$.

144 Vgl. ebd., $395 \mathrm{f}$.

145 Vgl. ebd., 397.

146 Vgl. ebd., $397 \mathrm{f}$.

147 Vgl. ebd., $398 \mathrm{f}$.

148 Vgl. ebd., 399.

149 Vgl. ebd., 400.

150 Vgl. ebd., 294-308. 
glomerat von „Glück“ und „Sorgen“ mit sich. Die existentiellste Form, welche „das Mutterglück“ bedrohe, seien jedoch „ungeratene Kinder“. ${ }^{151}$ Damit meinte Hollander nicht unerzogene Kinder, sondern Kinder, die „in unlösbare Konflikte mit dem Staat und der Gemeinschaft geraten und ausgestoßen werden. “152 Diese Kinder seien nach alter Redensart „schlimmer als Brand, Pestilenz und Krieg zusammen." ${ }^{153}$

Die Lösung, um diesen „unglückliche[n] Einflüssen oder Zusammenflüssen von Eigenheiten und Eigenschaften“ vorzubeugen, die Schuld an der charakterologischen Entwicklung „ungeratener Kinder“ seien, sah Hollander im „Gesetz zur Verhütung erbkranken Nachwuchses“. Dieses „rassenhygienische“ Gesetz, das 1939 eingeführt wurde, um „Euthanasie“-Morde staatlich zu legitimieren, stelle, laut Hollander, den „erste[n], grundlegende[n] Versuch [dar], die Vernachlässigung eines Jahrtausends aufzuheben und die schlechten Erbströme zum Versiegen zu bringen.“154 „Das Glück, Kinder zu haben“, liege seit dem „Euthanasiegesetz“ nicht länger allein in der erzieherischen Verantwortung der Eltern, sondern sei staatlich geregelt - ein Umstand, den Hollander 1955 vordergründig ablehnte.

Hoppeler hingegen bevorzugte, wie oben gezeigt, eine christliche Erziehungsmoral. Diese sollte nach dem Vorbild „Christus [...] als höchste[m] Erzieher“ den Kindern Tugenden lehren, um den „Charakter [...] zu bilden und zu festigen“. ${ }^{155}$ Der ehemalige Nationalrat Hoppeler entließ seine Leser`innen nicht, ohne sie an die oben erwähnten „Pflichten“ und „Tugenden“ zu ermahnen. Gemeinsam mit ihren Kindern sollten die „Mütter“ dem staatlichen Auftrag nachkommen, im christlich-moralischen Sinne der Familienpolitik der „geistigen Landesverteidigung“ in einer selbsterzieherischen Optimierungspraktik ihren „Charakter [...] zu bilden und zu festigen“:

„Und nun, liebe Mütter, werte Erzieherinnen, wartet mit neuem Eifer eures hohen Amtes. Das Höchste, was aus der Hand des Schöpfers hervorging, ein Menschenkind, ist euch anvertraut. Fördert freudig, wo immer sich Gelegenheit bietet, die Kräfte seines Verstandes. Noch mehr aber laßt es eurer Anliegen sein, Gemüt und Wille, also den Charakter, so zu bilden und $\mathrm{zu}$ festigen, daß er den Stürmen unserer harten Zeit stand zu halten vermag, und immer

151 Vgl. Hollander 1940b, 227.

152 Vgl. ebd., 227.

153 Ebd., 227. Damit spielte Hollander wissenshistorisch auf den Dreißigjährigen Krieg an, der als „deutsches Trauma“ in die Geschichtsschreibung eingegangen war und, insbesondere im Kaiserreich des 19. Jahrhunderts. in Abgrenzung zur Staatsgründung von 1871, zur „deutschen Urkatastrophe“ hochstilisiert wurde. Vgl. Münkler 2017, Schmidt 2018.

154 Vgl. Hollander 1940b, 228.

155 Vgl. Hoppeler 1942, 571. 
ähnlicher werde dem Charakter dessen, der in seinem Erdenleben die Vollkommenheit verkörperte und der einst allem menschlichen Versagen und allem Leid ein Ende setzen wird: Christus. Er, der vom Schöpfer als höchster Erzieher dem Menschengeschlechte geschenkt ist, segne die Arbeit aller Mütter und Erzieherinnen unseres Schweizerlandes, und segne auch den Dienst, den unser Buch an ihnen ausrichten möchte."156

\subsection{Fazit}

Die transnationale Analyse von Frauen-, Paar- und Eheratgebern konnte aus einer geschlechterspezifischen Perspektive aufzeigen, wie der Inbegriff eines leistungsorientierten „Mutterglücks“, die Forderung an die „deutsche Mutter“, eine große Kinderschar zu zeugen, im unauflösbaren Widerspruch zu den emanzipatorischen Forderungen der NS-Frauenpolitik stand. Die affirmative Gefühlspolitik eines „rassenhygienisch“ begründeten „Eheglücks“ und „Mutterglücks“ als opferbereiter Dienst an der „Volksgemeinschaft“ wurde höher bewertet als das „Arbeitsglück“ der „deutschen Frau“ oder ihre gesellschaftliche Gleichstellung gegenüber dem „deutschen Mann“ innerhalb der ansonsten „gleichgeschalteten“ „NS-Volksgemeinschaft“. Auch in der Schweiz wurde im Rahmen der Familienpolitik der „geistigen Landesverteidigung“ das „Mutterglück“ favorisiert. Ratgeber, wie jener Hoppelers, begründeten diese Anweisung während des Zweiten Weltkriegs, im Unterschied zur „NS-Rassenpolitik“, auf christlichen-konservativen und humanistischen Moralvorstellungen. Die Erziehung der Kinder im Sinne der politischen Arbeitsmoral des jeweiligen Landes wurde in erster Linie den Müttern übertragen. In NS-Deutschland wurde die Erziehungsaufgabe zudem durch diverse NS-Organisationen ergänzt. Es gab aber auch Ausnahmen: Wie das Beispiel des Ratgebers der Schweizer Arbeitspsychologin Baumgarten zeigt, bewertete die Professorin „Erfolg“ in erster Linie aus der Perspektive eines persönlich erlangten „Glücks“, in Abhängigkeit zu den charakterologischen Eigenschaften eines Menschen und nicht im Sinne normativer Geschlechterstereotypen und gesellschaftlicher Moralvorstellungen über „Arbeitsglück“, „Eheglück“ oder „Mutterglück“.

Die folgende Anekdote aus dem Eheratgeber „Ein Leben zu Zweien“ (1940) von Hollander leitet in den III. Hauptteil über eine Politik der ,Glückskulturen in der Theaterpolitik, Theaterwissenschaft und Theaterpraxis über. Hollander begann seinen Eheratgeber mit der Schlüsselszene eines autobiografischen Erlebnisses im Berliner Staatstheater:

156 Ebd., 571. 
„In der reizenden Neuformung von Goldonis ,Lügner im Berliner Staatstheater hatte eine der Figuren einen Satz gegen die Ehe zu sagen: ,Kein Mann ist bei Vernunft, wenn er einer Frau die Ehe verspricht.' Das ist ein ziemlich belangloser und nicht sehr geistreicher Satz. Seltsamerweise erzielte er einen orkanartigen Beifall. Gleichmäßig begeistert klatschten Männer und Frauen. In der Pause konnte man feststellen, daß die begeisterten Klatscher größtenteils Ehepartner waren. Junge, alte und ganz alte, eben verheiratete, die noch nett miteinander waren, abgebrühte, die noch gerade höflich nebeneinander hergingen, und nicht wenige, bei denen die Frau immer einen Schritt hinter dem Mann herging, so, als dürfte sie ihn nicht durch ihren Anblick beleidigen. Alle diese verheirateten Menschen hatten dem frechen Satz Goldonis so beigestimmt, als ob er ihnen eine ganz neue Erkenntnis vermittelte, eine Offenbarung von Dingen, die sie dumpf spürten, aber nicht ausdrücken konnten oder nicht zu sagen wagten. “157

„Man kann solche und ähnliche Erlebnisse in allen Theatern [...] haben“, stellte der erfahrene Eheberater 1940 fest. ${ }^{158}$ In seiner Beschreibung eines Berliner Theaterabends benennt der Ratgeberautor zentrale Merkmale einer theaterästhetischen Wirkungsmacht zwischen darstellenden Schauspieler*innen und beobachtenden Zuschauer`innen während und nach einer Aufführung: Ein Abend im Theater könne „neue Erkenntnisse“ auf scheinbar Altbekanntes vermitteln. Wie? Indem eine Aufführung „Offenbarungen von Dingen“ lieferte, welche die Zuschauer`innen „dumpf verspürten, aber nicht ausdrücken konnten oder nicht zu sagen wagten. " ${ }^{159}$ Die affirmativen Gefühlsregungen im Zuschauerraum nimmt der Ratgeberautor zum Anlass, um dem gesellschaftlichen Phänomen auf den Grund zu gehen, warum „Ehewitze“160 und „ehefeindliche Aussagen“161 für Gelächter beim Publikum sorgten.

„Alle die Männer und Frauen, die da lachen und Beifall klatschen, würden höchst erstaunt sein, wenn man ihnen klarmachte, daß sie gegen die Einrichtung der Ehe demonstrieren. Sie würden den Vorschlag, die Ehe in der jetzigen Form abzuschaffen, wenn sie den meisten Menschen doch so unzulänglich erscheint, als abwegig ablehnen.“162

Die existentiellen Fragen nach „Liebesglück“, „Eheglück“, „Mutterglück“ oder „Arbeitsglück“, wie sie auf der Theaterbühne verhandelt wurden, geben, aller Vergnügtheit zum Trotz, einen Einblick in die geschlechterpolitischen Zustände jener Zeit. Ein Glückswissen über das Eheleben wurde ironisiert auf der Schau-

157 Hollander 1940b, 11.

158 Vgl. ebd.

159 Vgl. ebd.

160 Ebd.

161 Ebd., 13.

162 Ebd., 12. 
bühne zur Diskussion gestellt und vom Publikum emotionspolitisch rezipiert. Zieht man die totalitären Verhältnisse in Betracht, unter welchen die Aufführung im „gleichgeschalteten“ Theaterbetrieb des NS-Regimes vor dem Hintergrund der „rassenhygienischen“ Ehe- und Geburtenpolitik stattfand, wird das emotionspolitische Wirkungspotential der darstellenden Künste als Teil einer kulturellen Wissenszirkulation von Glückswissen deutlich. Diesem Untersuchungsfeld widmet sich der III. Hauptteil. 
